\title{
Imaging of endometrial and cervical cancer
}

\author{
Shilpa Patel • Sidath H. Liyanage • Anju Sahdev • \\ Andrea G. Rockall • Rodney H. Reznek
}

Received: 18 July 2010 / Accepted: 13 September 2010 /Published online: 28 September 2010

(C) European Society of Radiology 2010

\begin{abstract}
In this article we review the ever increasing role of imaging in endometrial and cervical cancer. Magnetic resonance imaging (MRI) has emerged as the most widely used technique in the management of women with gynaecological cancer. In endometrial cancer, MRI is reliable in identifying myometrial and cervical invasion and extra-uterine disease, thereby informing preoperative surgical planning. In cervical cancer, MRI plays a crucial role in distinguishing early from advanced disease, thereby stratifying patients for surgery and chemoradiation. MRI is also valuable in assessing proximal extension of cervical tumours in young women with early stage disease for feasibility of fertility preserving surgery. In both cancers, imaging is used for diagnosing nodal metastases, detection of recurrence, and dealing with complications of both the disease and treatment.
\end{abstract}

Keywords Endometrial cancer · Cervical cancer · MRI · FIGO staging $\cdot$ Lymph nodes

\section{Introduction}

Although both cervical and endometrial cancers arise in the uterus, the tumours have quite different aetiologies and

S. Patel $(\bowtie) \cdot$ S. H. Liyanage $\cdot$ A. Sahdev $\cdot$ A. G. Rockall

R. H. Reznek

Department of Radiology,

King George V Wing,

Barts and The London NHS Trust,

St Bartholomew's Hospital,

West Smithfield, London EC1A 7BE, UK

e-mail: shilpa979@doctors.org.uk clinical features. Diagnosis is initially made at histology in both cancers. Imaging is an important adjuvant to clinical and surgical evaluation. Transvaginal ultrasound (TVUS) for endometrial cancer, computed tomography (CT), magnetic resonance imaging (MRI), and ${ }^{18} \mathrm{~F}$-fluorodeoxyglucose positron emission tomography (FDG-PET) have a significant impact in the management of patients with endometrial and cervical cancer. The role of imaging includes tumour staging, treatment planning, assessing treatment response, and detecting treatment complications and recurrent disease. For imaging to be used effectively, however, it is important for the radiologist to understand not only the treatment options with which the multidisciplinary team and the patient are faced but also the diagnostic performance, advantages and limitations of each of these imaging modalities.

The most widely used staging classification is that of the International Federation of Gynaecology and Obstetrics (FIGO). In this article, we review the recent changes to the FIGO staging classification and discuss the increasing reliance on imaging in the management of patients with endometrial and cervical cancer with a particular emphasis on the role of MRI in primary staging and detecting disease recurrence.

\section{Endometrial cancer}

Carcinoma of the endometrium is the most prevalent gynaecological malignancy in Western Europe and North America and its incidence is climbing due to increased life expectancy and rises in obesity [1,2]. Endometrial carcinoma primarily presents in the 6th-7th decades, with only very few women diagnosed under the age of 35 [3]. Despite being a relatively common malignancy, it is not a 
leading cause of cancer death, with a 10 -year survival rate of $75 \%$, partly because $75-80 \%$ of women present at an early stage with postmenopausal bleeding [3].

Several recognised risk factors are associated with endometrial cancer. Any condition which results in prolonged unopposed oestrogen stimulation of the endometrial lining can predispose to endometrial neoplasia. Oestrogen excess can be exogenous (unopposed oestrogen therapy) or endogenous, such as in patients with ovarian malfunction, those with oestrogen secreting tumours or in obese patients [4]. Long-term use of tamoxifen citrate and nulliparity are also associated with increased risk $[5,6]$.

Following presentation, TVUS is widely accepted as the initial imaging modality. Careful assessment of endometrial thickness, with an abnormal threshold of $5 \mathrm{~mm}$ or greater, provides a sensitivity of higher than 95\% [7]. If the endometrium is thickened or bleeding continues, sampling of the endometrial lining is undertaken. Histopathological diagnosis and tumour grade can either be obtained as an outpatient, using a pipelle biopsy sampling technique, or by hysteroscopic assessment with dilatation and curettage in theatre.

A recent study by Todo et al. [8], which reviewed 671 patients with endometrial carcinoma, more than $90 \%$ were found to have adenocarcinomas. Of these, $52 \%$ were Grade 1 tumours (well differentiated), 25\% were Grade 2 tumours (moderately differentiated) and 15\% were Grade 3 (undifferentiated) carcinomas. The remaining $8 \%$ were associated with a poorer prognosis and included clear cell carcinoma and serous adenocarcinoma [8]. The prognosis of endometrial carcinoma depends on the age of the patient, histological tumour grade, cell type, tumour stage and lymph-node status $[9,10]$. New data from the study by Todo and co-workers supports these findings where the presence of para-aortic nodal metastasis has the most impact on prognosis (hazard ratio of 3.07 compared with a hazard ratio of 1.81 for age over 56 years and a hazard ratio of 1.87 for Grade 3 or non-endometriod histology) [8].

Table 1 [11] summarises the risk factors for pelvic and para-aortic lymph-node metastases which depend on the depth of myometrial and cervical invasion, tumour grade and tumour occupying more than one-third of the endometrial cavity. The depth of myometrial and cervical stromal invasion are therefore key prognostic factors due to an association with nodal metastases. Creasman et al. [10] demonstrated in Grade 3 tumours that there was a 9\% incidence of nodal metastases if only superficial myometrial invasion was present (involving the inner third), but this figure increased to $34 \%$ when deep myometrial invasion was present (involving the outer third). The depth of myometrial invasion is also a strong prognostic factor regarding the 5-year survival rate. In patients with no myometrial invasion and low-grade histology, the 5-year survival rate is $95 \%$, compared with $42 \%$ in patients with tumour invasion extending into the outer half of the myometrium and high grade histology [1].

\section{Staging and treatment}

Clinical staging of endometrial carcinoma is inaccurate and often underestimates the extent of disease [12]. As a result, FIGO staging of endometrial cancer was reclassified in 1988 as a surgico-pathological staging system [13] and was again revised in 2009 (Table 2) [14, 15]. Therefore full FIGO staging requires a total abdominal hysterectomy (TAH), bilateral salpingo-ophrectomy (BSO), peritoneal washings, assessment and sampling of pelvic and para-aortic lymph-nodes. This surgico-pathological staging system is independent of radiological staging or assessment.

Conventional treatment of endometrial cancer performed in most patients is TAH and BSO with peritoneal washings and this is the current FIGO staging method for full staging of the tumour. Lymphadenectomy remains a component of the surgical-pathological staging of endometrial cancer. However, as recently stated by Dowdy et al. [16], 'the lack of consensus for primary surgical treatment for endometrial cancer, the most common gynaecological malignancy, is deplorable'. The disadvantage of lymphadenectomy is that it carries a significant complication rate of $17-19 \%$, requires increased anaesthetic and operating times and needs the expertise of a specialised oncologic surgeon [17, 18]. The rate of pelvic lymph node involvement in Stage I endometrial cancer (i.e. confined to the corpus) is low at approximately $10 \%$ [19]. Although nodal metastases have been dectected in up to $29 \%$ of patients in intermediate to high risk categories in a recent series [8]. Patient selection for primary lymphadenectomy at the time of hysterectomy is, therefore, presently controversial in oncological gynaecology. In some centres, the majority of patients undergo surgical lymphadenectomy [8]. Conversely, lymphadenectomy is not widely practiced in the UK and is variable in the US, where there is a much lower rate of lymphadenectomy by gynaecologists $(26 \%)$ and specialist gynaecologic oncologists $(83 \%)$ [20, 21].

In many centres, surgical planning is dependent upon prognostic risk factors. Patients at low risk of extrauterine spread (Grade 1 or 2 histology, new FIGO Stage $<1 \mathrm{~B})$ may be treated with TAH and BSO alone. In these cases, formal lymphadenectomy is not always performed, however any suspicious appearing nodes on imaging or at surgery will be resected. This policy is supported by findings of two recently published trials. A randomised clinical trial assessing lymphadenectomy versus no lymphadenectomy in Stage I endometrial carcinoma demonstrated no improvement in disease free or overall survival following 
Table 1 Risk groups for pelvic and para-aortic nodal disease in endometrial cancer

\begin{tabular}{ll}
\hline Risk Group & Features \\
\hline High & Any age and all three features listed below: \\
& 1. Grade 3 adenocarcinoma \\
& 2. $>50 \%$ deep myometrial invasion \\
& 3. Lymphovascular space invasion \\
& $>50$ years and any two of the above features \\
Intermediate & $>70$ years and any one of the above features \\
& Grade 1 and 2 adenocarcinoma and no or superficial myometrial invasion \\
\hline
\end{tabular}

lymphadenectomy [22]. Similarly, the ASTEC trial demonstrated no benefit in overall survival or recurrence-free survival with pelvic lymphadenectomy in women with Stage I endometrial cancer [19]. In patients with high risk disease (Grade $>2$, new FIGO Stage $>1 \mathrm{~A}$ ), full surgical staging, including lymphadenectomy is recommended. The validity of these trial results has been questioned in view of relatively short duration of follow-up and limited extent of lymphadenectomy (nine or fewer nodes were removed in $35 \%$ of patients).

A large retrospective study from Japan has challenged the findings presented by Kitchener et al. [19] and Benedetti et al. [8, 22]. Toda et al. [8] reported a significant improvement in overall, disease-specific and recurrencefree survival in patients with intermediate or high risk disease who undergo complete pelvic and para-aortic nodal dissection compared with pelvic dissection alone. Despite these published findings, there is still a range of practice concerning resection of lymph nodes and this procedure remains part of the formal staging of disease.

Controversy still surrounds the use of adjuvant therapy in endometrial carcinoma and there is no consensus [23]. Studies have shown in patients with low or intermediate risk disease that external beam radiotherapy (EBRT) can reduce the risk of pelvic relapse, but it has no impact on overall survival [24]. However, EBRT is associated with a $10 \%$ survival advantage in patients with high risk disease [25]. Vaginal brachytherapy (VBT) is associated with reduced toxic effects and a recently published randomised trial has demonstrated that VBT is as effective as EBRT for the prevention of vaginal recurrence following surgery in high- to intermediate-risk patients and therefore should become the standard of care [26] Chemotherapy can be used in patients with aggressive histological subtypes,

Table 2 FIGO staging of endometrial carcinoma and corresponding MR findings (revised 2009)

\begin{tabular}{|c|c|c|}
\hline $\begin{array}{l}\text { FIGO } \\
\text { Stage }\end{array}$ & Description & MRI findings \\
\hline Stage $\mathrm{I}^{\mathrm{a}}$ & Tumour confined to the corpus uteri & \\
\hline IA & Tumour extending to $<50 \%$ of myometrial depth & $\begin{array}{l}\text { Signal intensity of tumour extends into }<50 \% \text { of myometrium. } \\
\text { Partial or full thickness disruption of the junctional zone }\end{array}$ \\
\hline IB & Tumour extending to $>50 \%$ of myometrial depth & $\begin{array}{l}\text { Signal intensity of tumour extends into }>50 \% \text { of myometrium. } \\
\text { Full thickness disruption of the junctional zone }\end{array}$ \\
\hline Stage II $^{\mathrm{a}}$ & $\begin{array}{l}\text { Tumour invades cervical stroma, but does not extend } \\
\text { beyond the Uterus }\end{array}$ & $\begin{array}{l}\text { Internal os and endo-cervical canal are widened. } \\
\text { Disruption of low signal stroma }\end{array}$ \\
\hline Stage III $^{\mathrm{a}}$ & Local and/or regional spread of the tumour & \\
\hline IIIA & $\begin{array}{l}\text { Tumour invades the serosa of the corpus uteri and/or } \\
\text { adenexae }\end{array}$ & $\begin{array}{l}\text { Disruption of continuity of outer myometrium. Irregular uterine } \\
\text { configuration }\end{array}$ \\
\hline IIIB & Vaginal and/or parametrial involvement & Segmental loss of hypointense vaginal wall \\
\hline IIIC & Metastases to pelvic and/or para-aortic lymph nodes & Regional or para-aortic nodes $>1 \mathrm{~cm}$ in short axis diameter \\
\hline IIIC1 & Positive pelvic nodes & \\
\hline IIIC2 & $\begin{array}{l}\text { Positive para-aortic lymph nodes } \pm \text { positive pelvic lymph } \\
\text { nodes }\end{array}$ & \\
\hline Stage IV & $\begin{array}{l}\text { Tumour invades bladder and/or bowel mucosa, and/or } \\
\text { distant metastases }\end{array}$ & \\
\hline IVA & Tumour invasion of bladder and/or bowel mucosa & Tumour nodules protruding in the bladder/rectal lumen \\
\hline IVB & $\begin{array}{l}\text { Distant metastases, including intra-abdominal metastases } \\
\text { and/or inguinal lymph nodes }\end{array}$ & Tumour in distant sites or organs \\
\hline
\end{tabular}

${ }^{\text {a }}$ Positive cytology obtained at peritoneal washings should be recorded but does not alter any stage 
either in the context of a clinical trial (PORTEC 3) or as a palliative measure [23].

\section{Imaging}

The ability to select patients for lymphadenectomy prior to surgery may, therefore, be of value. Imaging can assist in preoperative assessment and surgical planning by predicting the depth of myometrial invasion, cervical stromal involvement, distant spread and lymph-node involvement. Preoperative knowledge of these factors is important, as patients with disease greater than FIGO Stage 1A may benefit from lymphadenectomy, but the number of unnecessary lymph-node dissections can also be reduced in low risk patients by showing that none of these factors are present [27].

Histological diagnosis before staging is essential, as imaging cannot accurately differentiate endometrial carcinoma from polyps or hyperplasia [28].

TVUS has been used to evaluate the depth of myometrial and cervical invasion, but this is operator-dependant and, thus, the reported accuracies vary between 77-91\% [29]. As there is relatively little contrast difference between tumour and myometrium, CT is not sensitive or specific enough to assess the depth of myometrial or cervical involvement. For detection of deep myometrial invasion, the sensitivity and specificity are $83 \%$ and $42 \%$, respectively [30], with an overall staging accuracy of between $58-76 \%$ [31]. CT performs as well as MRI in identifying extrauterine spread and identifying nodal metastases [32].

MRI is considered the most accurate imaging modality for preoperative assessment of endometrial carcinoma due to its excellent soft-tissue contrast resolution. Overall accuracies have been reported at $83-92 \%$ [33, 34]. MRI is probably of greatest value in evaluating tumours that may be at risk of extrauterine spread, where a tumour mass is seen at ultrasound and histology is Grade 2 or 3. The MRI findings corresponding to the FIGO Stage of endometrial cancer are summarised in Table 2.

\section{MRI technique and tumour appearance}

Patients are asked to fast for 4-6 h and antiperistaltic agents may be used to limit peristaltic artefact from the bowel [35]. High-resolution T2-weighted images are obtained in the sagittal plane and oblique axial plane (small field of view), perpendicular to the endometrial cavity, to enable assessment of depth of myometrial and cervical invasion. Following injection of contrast medium, fat-saturated T1weighted images, ideally in the sagittal and axial oblique plane, have been shown to significantly improve pretest probability of myometrial invasion in all grades of adenocarcinoma [36]. Dynamic post-contrast T1-weighted images are also helpful in distinguishing between the enhancement of tumour, subendometrial mucosal layer and myometrium. Optimal tumour to myometrial contrast usually occurs at $50-120 \mathrm{~s}$ after injection of contrast medium, with myometrium enhancing more than the invading tumour [36]. Wide field-of-view images of the upper abdomen are obtained to look for para-aortic lymph nodes, metastases and any complications, such as hydronephrosis [37].

The normal zonal uterine anatomy is clearly delineated on T2-weighted imaging, where the normal endometrium is of high signal intensity, with a low signal intensity junctional zone and intermediate signal intensity of the myometrium. Endometrial carcinoma is usually isointense to the myometrium on T1-weighted sequences and of lower signal intensity than the endometrial lining on the T2weighted sequences. On T1-weighted post-contrast images, the tumour typically enhances less than normal myometrium, and on dynamic contrast enhancement enhances more slowly than myometrium.

Pitfalls in staging of endometrial carcinoma on MRI include blood in the endometrial cavity due to recent dilatation and curettage or tumour haemorrhage, extreme thinning of the myometrium, poor natural contrast between the tumour and myometrium, adenomyosis and leiomyomata $[11,38]$.

\section{Preoperative staging on MRI}

The criteria used in FIGO staging system may be applied to preoperative MRI. Stage 0 has been removed recently from the FIGO staging classification [14].

\section{Stage I}

Stage I tumours are confined to the uterine corpus, comprising over $80 \%$ of cases. In Stage IA disease, there is typically focal or diffuse thickening of the endometrium by tissue that has lower signal intensity than normal endometrium. Myometrial invasion (of less than $50 \%$ for Stage IA) may be diagnosed when the intermediate signal of the tumour is seen breeching the junctional zone and extending into the myometrium on T2-weighted and postcontrast images (Figs. 1 and 2). Subtle irregularity may be seen between the margin of the tumour and the junctional zone in cases of early invasion. In cases where the junctional zone is not visible or indistinct, a smooth interface between the endometrium and myometrium is considered to represent an intact myometrium.

When the tumour disrupts the junctional zone and is seen to extend more than $50 \%$ into the deep myometrium, it is classed as Stage IB disease (Fig. 3); however, an outer stripe of normal myometrial tissue remains intact $[28,39]$. 
Fig. 1a, b Endometrial cancer FIGO 1A. a Sagittal and b oblique axial T2-weighted MRI. There is intermediate T2 signal intensity soft tissue within the endometrium (arrows). No breach of the junctional zone is visible and the interface between the tumour and junctional zone is well defined
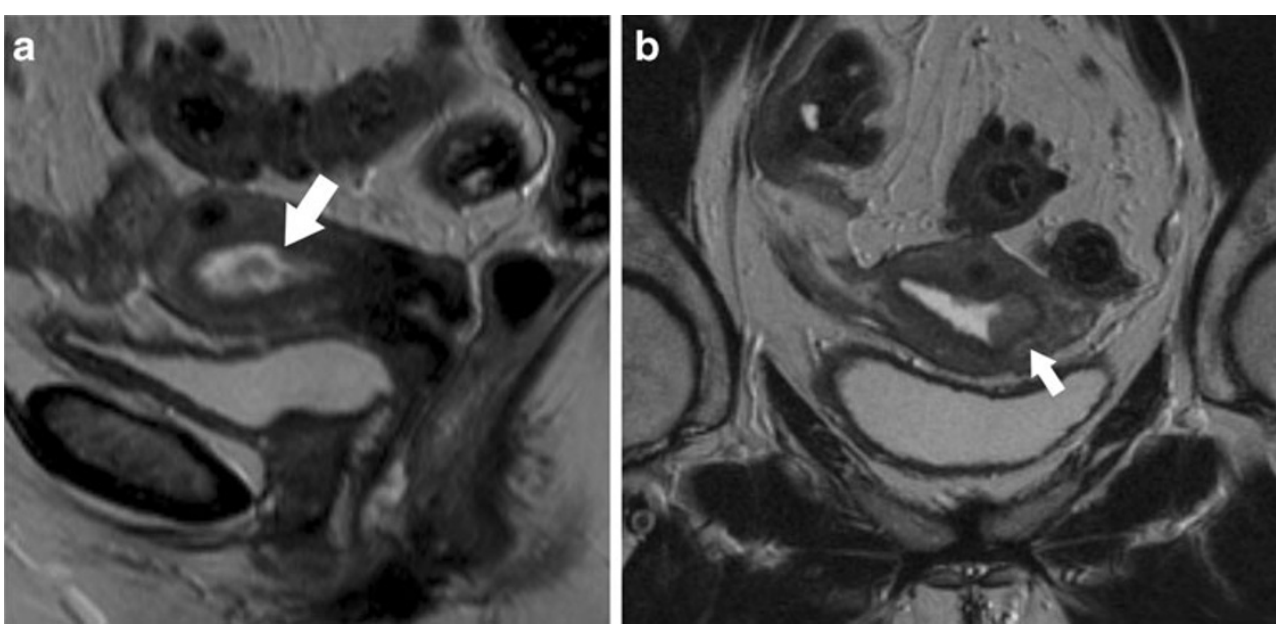

The degree of invasion should be assessed on both T2weighted images in the sagittal and oblique axial views as well as post-contrast images.

\section{Stage II}

Stage II disease is direct invasion of the cervical stroma (Figs. 4 and 5). Identification is important as $50-67 \%$ of patients with cervical stromal invasion have lymph-node involvement or other sites of extrauterine disease [40, 41]. Normal cervical stroma is hypointense on T2-weighted imaging and endometrial carcinoma is intermediate to hyperintense. The assessment of cervical involvement may be improved on late dynamic post-contrast T1-weighted imaging, which can help distinguish between true invasion and a protruding polypoid tumour into the endocervical canal [42]. In Stage II disease, tumour extends into and widens the endocervical canal and internal os with disruption of the fibrocervical stroma. The overall accuracy of MRI in predicting cervical involvement is reported as $90-92 \%$, with sensitivities of $75-80 \%$ and specificities of 94-96\% [43-45].

\section{Stage III}

Stage III is disease outside the uterus but not beyond the true pelvis. In Stage IIIA disease, invasion of the uterine serosa or adnexae is identified (Fig. 6). On the T2-weighted images, tumour may be seen to extend beyond the outer margin of the uterus and, on the contrast-enhanced T1weighted images, there is loss of the normal rim of brightly enhancing myometrium. Tumour deposits in the ovaries, even in the absence of serosal invasion may also be identified. In the revised FIGO staging, positive peritoneal cytology from peritoneal washings alone does not constitute Stage IIIA disease.

In Stage IIIB disease, there is tumour involvement of the vagina or parametria, either by direct extension or as
Fig. 2a, b Endometrial cancer FIGO IA. a Sagittal T2-

weighted and $\mathbf{b}$ para-sagittal post-contrast images. There is a large volume of tumour within the endometrial cavity. There is invasion of the myometrium, extending to $<50 \%$ of the myometrial thickness (arrow). The post-contrast image demonstrates the typical bright enhancement of the myometrium with intermediate enhancement of the tumour
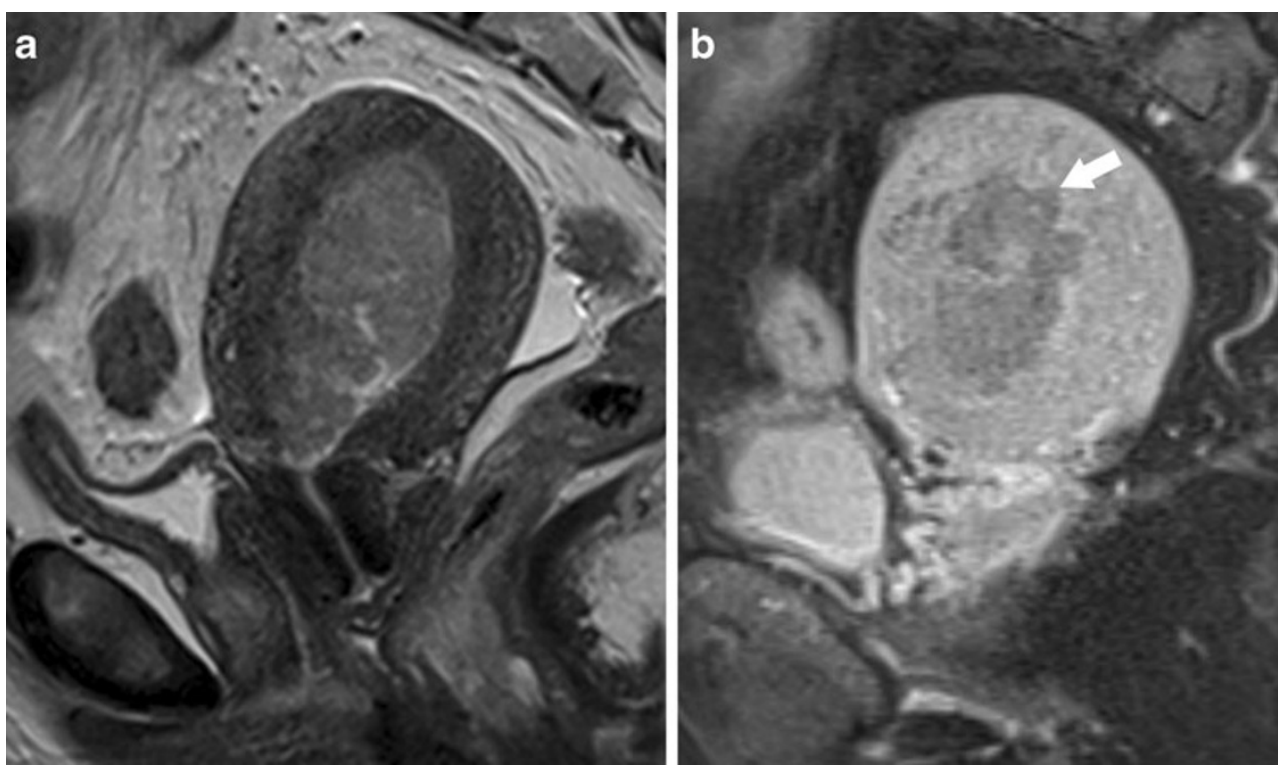
Fig. 3a, b Endometrial cancer FIGO IB. a The tumour (arrow) is poorly defined on the T2weighted image, in this case. Depth of myometrial invasion is difficult to assess. b Dynamic post contrast image clearly defines the brightly enhancing myometrium from the tumour. The depth of myometrial invasion is greater than $50 \%$ (arrows)
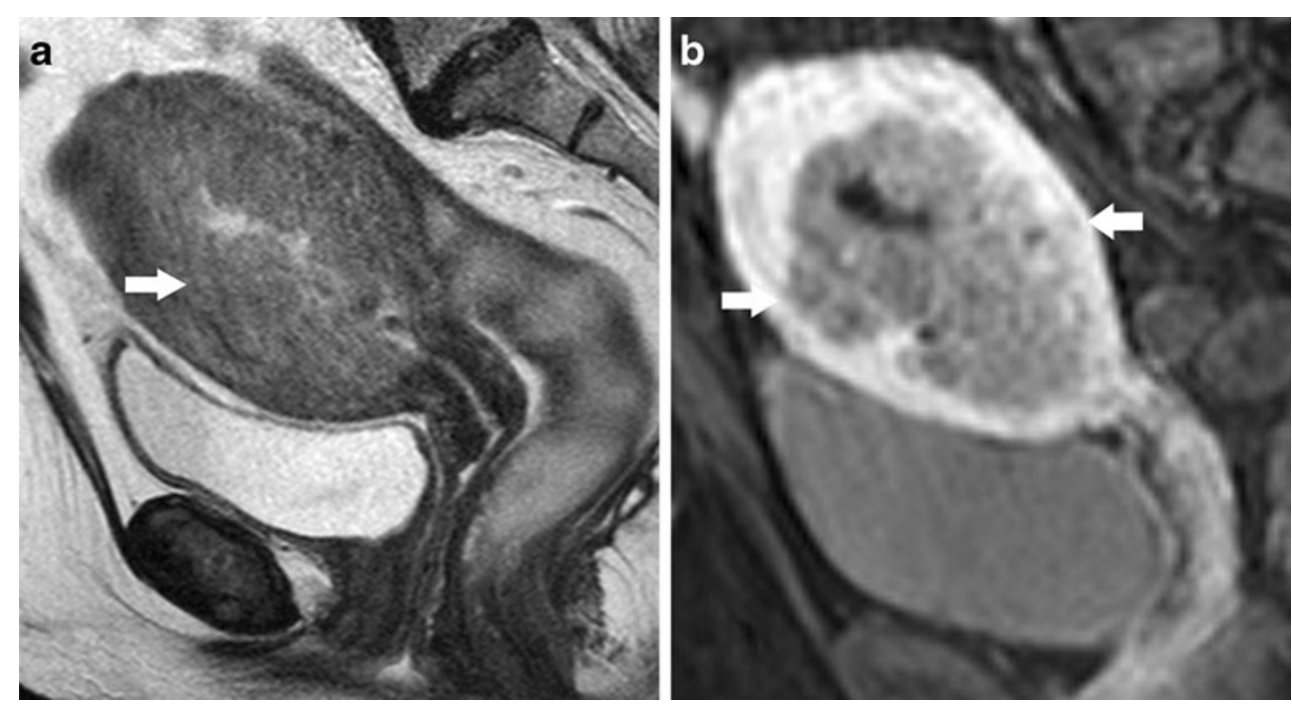

metastatic disease. On T2-weighted images, intermediate signal intensity tumour invading through the low signal intensity vaginal wall is seen.

Regional nodal involvement indicates Stage IIIC disease; IIIC1 indicates involvement of pelvic nodes (Fig. 7), whereas Stage IIIC2 indicates positive para-aortic nodes, with or without pelvic nodal involvement. Lymph-nodes are hypointense on T1-weighted images and intermediate intensity on T2-weighted imaging [46]. Nodal metastases correspond to drainage sites of involved portions of the uterus. The middle and lower aspects drain to the parametrium, paracervical and obturator nodes. The upper corpus and fundus drain to common iliac and para-aortic lymph-nodes. The diagnosis of nodal involvement on CT and MRI uses size criteria with a cut off of $1 \mathrm{~cm}$ minimum axial diameter. This results in a low sensitivity for detection

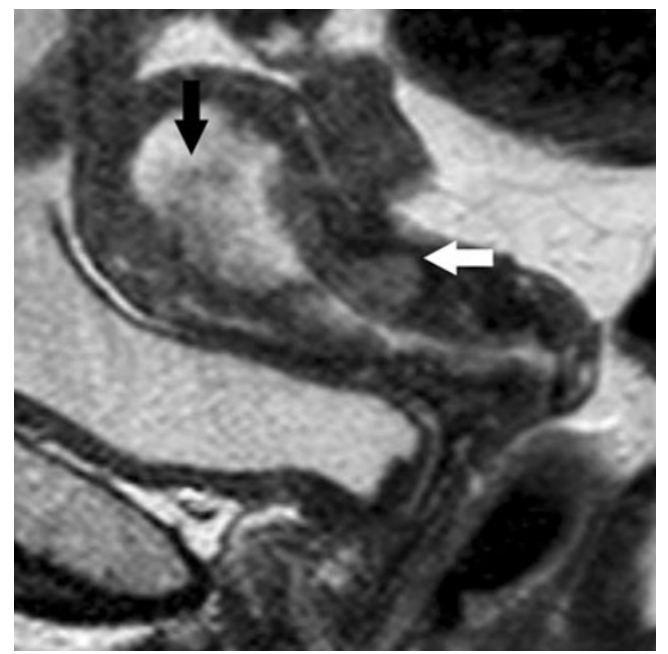

Fig. 4 Endometrial cancer Stage II. Sagittal T2-weighted image demonstrates tumour in the endometrial cavity (black arrow) which extends into the endocervical canal and invades the upper cervical stroma (white arrow) at the internal os of lymph-node metastases and diagnosis on MRI remains unsatisfactory $[44,46]$.

\section{Stage IV}

Direct infiltration of the bladder or bowel mucosa is Stage IVA disease (Fig. 8). This is seen as loss of the low signal intensity wall of the bladder or rectum on T2-weighted images and tumour nodules in the mucosa of the invaded organ [42]. In Stage IVB disease, there are distant metastatic deposits or peritoneal deposits with or without inguinal lymph-node involvement. Peritoneal deposits may be outlined by ascites and are best seen on delayed contrast-enhanced images, but deposits of less than $1 \mathrm{~cm}$ may be difficult to identify on any imaging modality [42]. Distant spread to lung, liver and bones is rare at presentation and usually occurs haematogenously, the lung being the most common site involved.

\section{FDG-PET/CT}

The primary role for FDG-PET/CT is for detection of extrauterine disease. A study comparing MRI with FDG$\mathrm{PET} / \mathrm{CT}$ demonstrated no statistically significant difference in the detection of lymph-node metastases in patients with endometrial carcinoma [47]. There was a high negative predictive value for nodal involvement (94-96\%) on both imaging modalities. FGD-PET/CT did, however, detect distant metastatic disease with a sensitivity of $100 \%$ and a specificity of $94 \%$ [24, 47]. FDG-PET/CT is not generally considered sensitive enough to replace lymph-node dissection.

\section{Recurrent disease}

Endometrial carcinoma has a low rate of recurrence of $4-16 \%$ $[8,24]$. Factors that predict relapse include advanced stage at presentation, high-grade histology, age over 60 years and 
Fig. 5a, b Endometrial cancer extending into the endocervical canal. a Sagittal and $\mathbf{b}$ oblique axial T2-weighted images demonstrate an intermediate signal intensity mass (black arrow). This lesion was thought to be confined to the endocervical canal but on histology there was minimal invasion of tumour into the cervical stroma (FIGO II). In retrospect, there is some thinning of the low signal intensity cervical stroma (white arrow). Minimal invasion of the stroma is difficult to report confidently and remains a potential pitfall
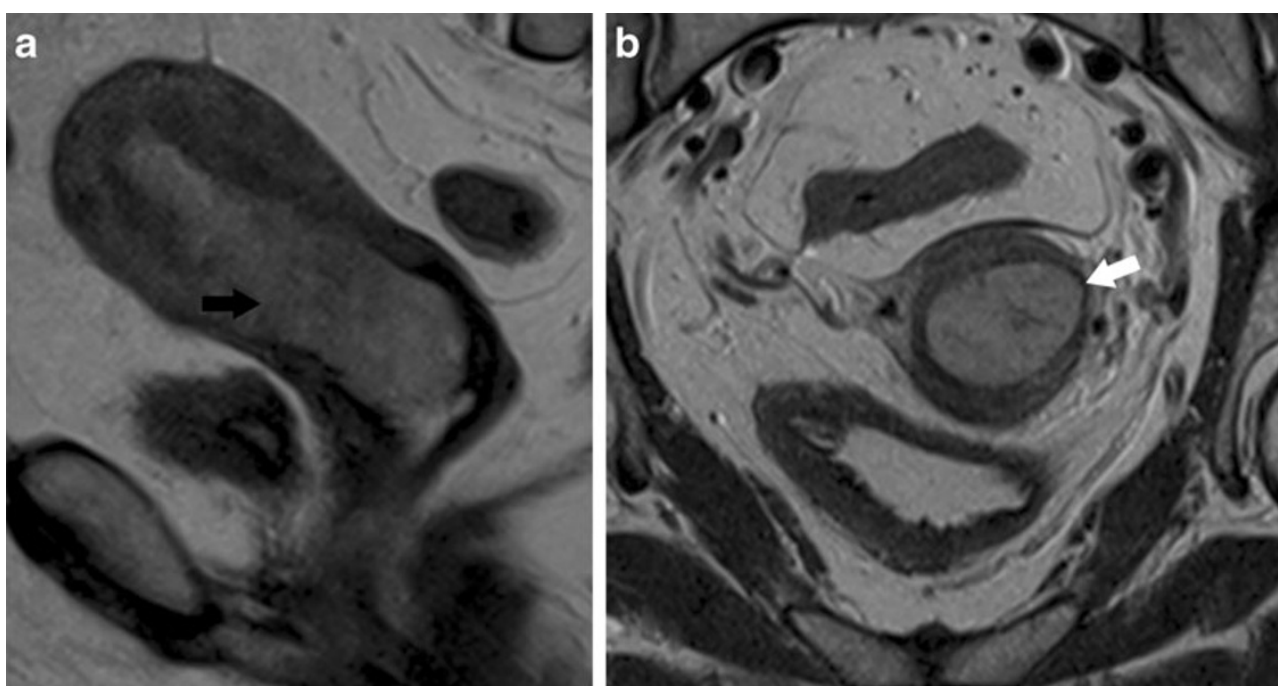

lymphovascualar invasion [24]. Following primary surgery, $64 \%$ of recurrences occur within 2 years and $87 \%$ within 3 years, the commonest sites being lymph nodes and vaginal vault (Fig. 9) [48]. Less frequently, it may manifest as peritoneal carcinomatosis (Fig. 10), or distant metastases in liver, lung or bones. Routine follow-up has a poor yield in detecting recurrence in the asymptomatic patient, but identification of those patients with an increased risk of recurrence and the likely time scale could direct an appropriate strategy for follow-up imaging.
Fig. 6a-d Endometrial cancer Stage IIIA. a Sagittal and b para-sagittal T2-weighted images demonstrate the tumour within the endometrial cavity (white arrow). To the left of midline, there is a tumour deposit lying along the peritoneal reflection between the uterus and bladder (black arrow). c Oblique axial T2-weighted image demonstrates the peritoneal mass (black arrow) as well as a mass in the right ovary (white ovary). d Axial T1-weighted image following administration of gadolinium demonstrates enhancement of the right ovarian deposit
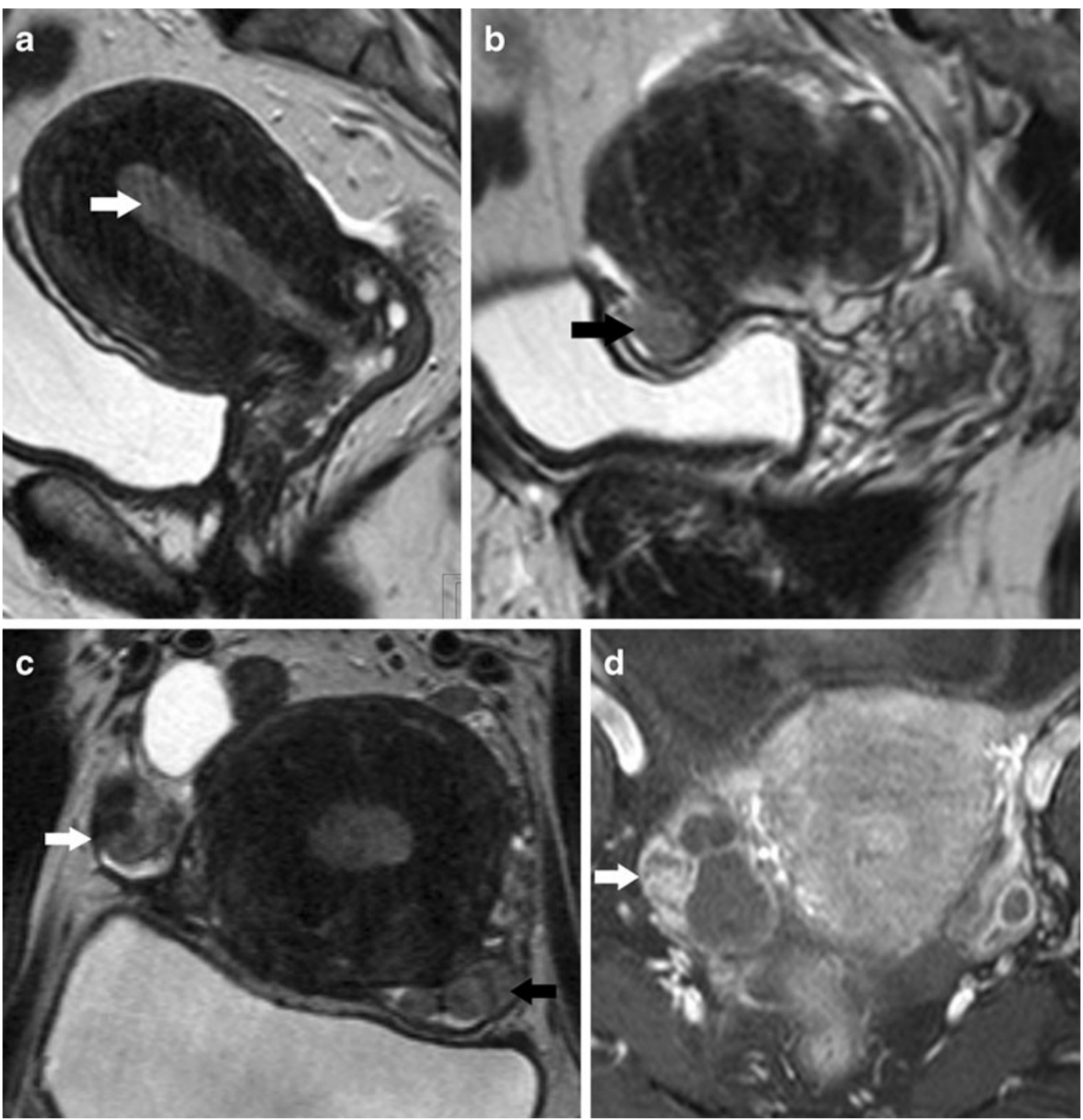
Fig. 7a, b Endometrial cancer FIGO IIIC1. a Sagittal T2weighted image demonstrates a tumour within the endometrial cavity (black arrow), which extends into the endocervical canal and invades the cervical stroma (white arrow). b Oblique axial T2-weighted images demonstrates an enlarged right external iliac lymph node (arrow)
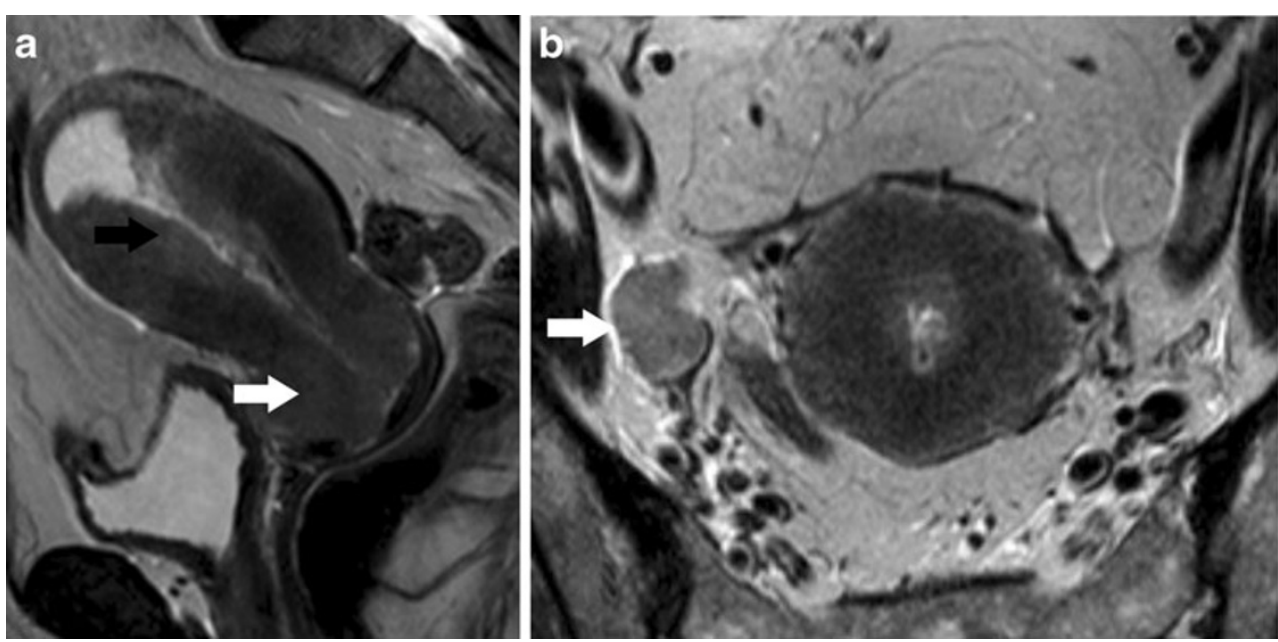

CT performs well in the detection of recurrent pelvic and distant disease, with an overall accuracy of 92\% [49]. MRI has also been advocated for this indication to evaluate surgical resectability. FDG-PET/CT has been shown to be helpful in the assessment of patients with suspected recurrence [50]. In one study, FDG-PET/CT detected unsuspected distant metastases in nine out of 26 patients which significantly altered the treatment choices [50]. A recently published study compared PET integrated with low-dose non-enhanced CT to PET integrated with contrast-enhanced CT [51]. It concluded that PET with contrast-enhanced CT is an accurate imaging modality for the assessment of uterine cancer recurrence and the use of contrast reduces the frequency of equivocal interpretations [51].

\section{Cervical cancer}

Cervix cancer remains one of the commonest cancers in women in developing countries, including Central and South America, parts of Africa, and South Central Asia [3]. During the last several decades, cervical cancer incidence and mortality rates have declined substantially in Western countries with the introduction of screening programmes, which detect pre-invasive disease on cervical smears [52]. However, the survival rates for patients who present with invasive cervical cancer have not improved over the same period. Younger women tend to present with earlier stages of the disease, with older women being diagnosed with later stages of the disease.

The most important aetiological factor is exposure to human papilloma virus (HPV), types 16 and 18 . The introduction of the vaccine against HPV 16 and 18 is likely to have a major impact on disease prevention [53]. Other risk factors include smoking, lower socio-economic class and the oral contraceptive pill. The commonest histological type is squamous cell carcinoma, which accounts for approximately two thirds of all cases and arises at the external os. Adenocarcinoma and adenosquamous carcinomas account for $10-25 \%$ of cases [3]. Most patients with invasive cervical cancer are asymptomatic at its early phase, and patients with advanced disease typically present with abnormal vaginal bleeding.
Fig. 8a, b Endometrial cancer FIGO IVA. a Sagittal and b oblique axial $\mathrm{T} 2$-weighted images demonstrate a large tumour replacing and distorting the uterus. There is breach of the uterine serosa and invasion of the adjacent sigmoid colon (black arrow) and pelvic sidewall (white arrow)
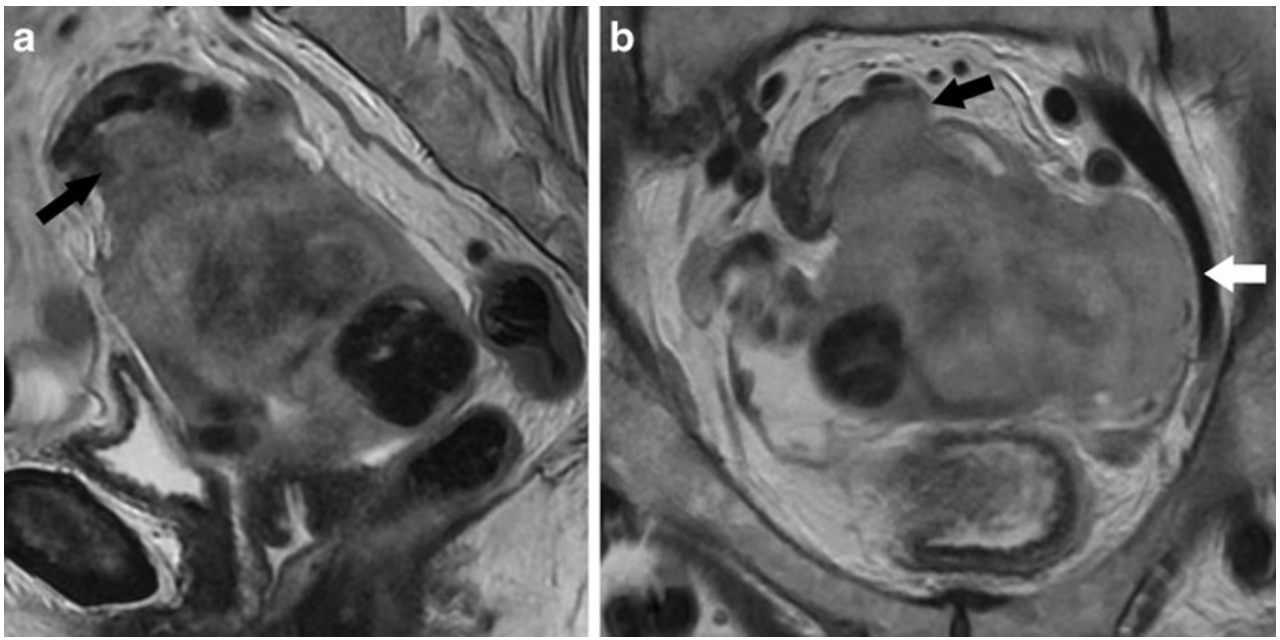


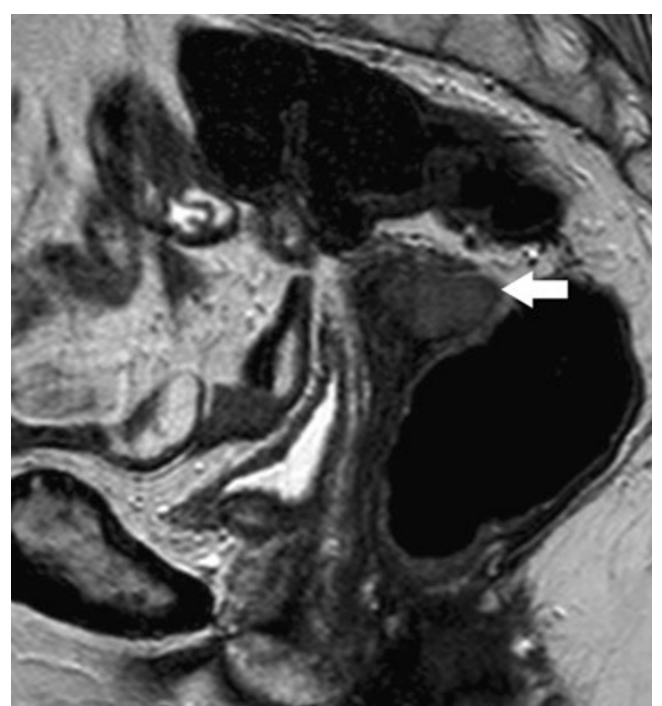

Fig. 9 Recurrent endometrial cancer. Sagittal T2-weighted image demonstrates a intermediate $\mathrm{T} 2$ signal intensity recurrent mass at the vaginal vault (arrow)

\section{FIGO staging and treatment}

The classic staging of cervical cancer uses the FIGO classification. The FIGO staging system has undergone a number of revisions over the past few decades, most recently in 2009 [14, 54] (Table 3). Unlike the staging of other gynaecological cancers, the FIGO staging of cervical cancer is entirely clinical and does not rely on surgico-pathological findings. This is mainly to achieve a staging system that is universally available and as cervical cancer is more prevalent in developing countries, only clinical methods are universally available. The staging procedure includes examination of the cervix under anaesthesia, colposcopy, biopsy, cystoscopy and sigmoidoscopy, although the last two are optional [14, 54].

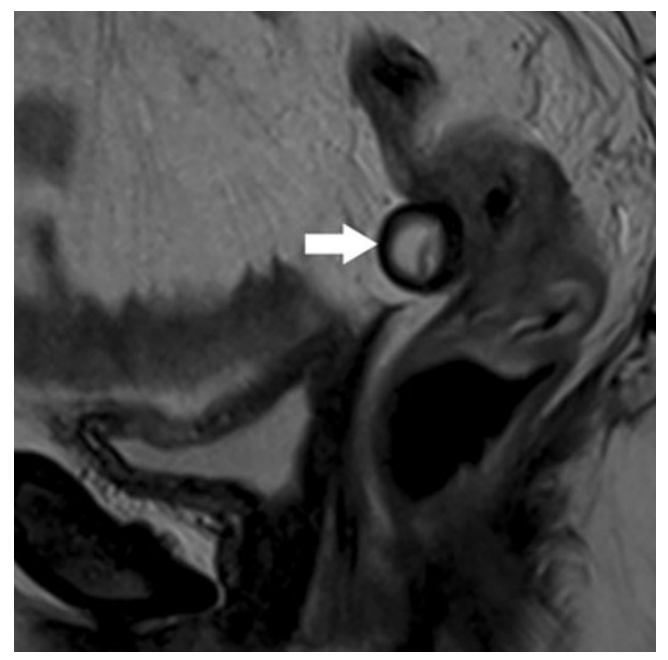

Fig. 10 Recurrent endometrial cancer. Sagittal T2-weighted image demonstrates serosal recurrence at the rectosigmoid colon (arrow)
Conventional radiographic techniques included are chest $\mathrm{X}$-ray, barium enema and intravenous urography. In the revised FIGO staging, incorporation of cross-sectional imaging (CT and MRI) is encouraged where available [14, 54].

Clinical staging is inherently inaccurate in evaluating several important staging parameters, including assessment of parametrial and pelvic sidewall invasion, accurate measurement of tumour size (particularly in endocervical or infiltrating tumours), and evaluation of lymph node metastases. Clinical staging errors occur in up to $25 \%$ of Stage I and Stage II disease; in 50-65\% of Stage IIA to IIIB disease; and in $67 \%$ of Stage IVA disease $[55,56]$. Overall, compared with surgery, clinical staging underestimates the stage in $25-67 \%$ of cases and overestimates in 2\% [55].

Accurate pre-treatment evaluation is not only important for prognosis but also for determining appropriate mode of treatment. The key decision in determining the patients management is whether or not the disease extends into the parametrium. In general, extension into the parametrium excludes primary surgery. However with greater targeting of conformal radiotherapy and the efficacy of chemoradiation larger tumours are increasingly being treated primarily with chemoradiation even without parametrial extension.

\section{Tumour staging on MRI}

Over the past several years, the role of MRI in gynaecological oncology has evolved. Owing to its superior soft tissue delineation, MRI is now the most widely used imaging modality in initial staging of primary cervical cancer. It is important in monitoring response and detecting recurrence, demonstrating complications of the disease itself and of treatment, determining feasibility of uterus-preserving surgery, and planning radiotherapy. Furthermore, it has also been demonstrated to be cost-effective by limiting or eliminating the need for further diagnostic tests or surgical procedures [57, 58].

The FIGO staging system can be readily applied to MRI appearances (Table 3).

\section{Stage I}

Stage IA (microinvasive) tumours usually show no visible disease on T2-weigthed images. The shape of the cervix maybe distorted due to diagnostic cone biopsy. Stage IB tumours appear as hyperintense or intermediate signal intensity mass relative to the low signal intensity of the cervical stroma on T2-weighted images. In young patients, in whom the cervix may have an intermediate signal intensity, delineation of the tumour can be challenging. Tumour of $4 \mathrm{~cm}$ or less is staged as IB1 (Fig. 11) and tumour greater than $4 \mathrm{~cm}$ is IB2 (Fig. 12). Size is an important determinant of patient management, as many 
Table 3 FIGO clinical staging of cervical carcinoma and corresponding MRI findings (Revised 2009)

\begin{tabular}{|c|c|c|}
\hline FIGO Stage & Description & MRI findings \\
\hline I & Tumour confined to cervix & \\
\hline IA & Microscopic invasive tumour & No evidence of tumour \\
\hline IA1 & Stromal invasion $\leq 3 \mathrm{~mm}$, width $\leq 7 \mathrm{~mm}$ & \\
\hline IA 2 & Stromal invasion $>3 \mathrm{~mm}$ but $\leq 5 \mathrm{~mm}$, width $\leq 7 \mathrm{~mm}$ & \\
\hline IB & $\begin{array}{l}\text { Clinically visible invasive tumour or pre-clinical tumours } \\
\text { greater than Stage IA }\end{array}$ & $\begin{array}{l}\text { Intermediate SI mass against low SI of the background } \\
\text { cervical stroma }\end{array}$ \\
\hline IB1 & Tumour $\leq 4 \mathrm{~cm}$ & \\
\hline IB2 & Tumour $>4 \mathrm{~cm}$ & \\
\hline II & $\begin{array}{l}\text { Invasion beyond uterus but not to pelvic side wall or } \\
\text { lower third of vagina }\end{array}$ & \\
\hline IIA & No parametrial invasion, upper two-thirds of vagina & $\begin{array}{l}\text { Loss of the normal low SI of the vaginal fornix or wall, usually } \\
\text { contiguous with the primary cervical tumour mass }\end{array}$ \\
\hline IIA1 & Tumour $\leq 4 \mathrm{~cm}$ & \\
\hline IIA2 & Tumour $>4 \mathrm{~cm}$ & \\
\hline IIB & Parametrial invasion & Breach of the low SI ring of the cervical stroma \\
\hline III & $\begin{array}{l}\text { Tumour extends to pelvic sidewall and/or involves the } \\
\text { lowest third of vagina }\end{array}$ & \\
\hline IIIA & $\begin{array}{l}\text { Tumour extends to lower third of vagina, not to } \\
\text { pelvic sidewall }\end{array}$ & $\begin{array}{l}\text { Loss of the normal low SI of the vaginal wall in the } \\
\text { lower third of vagina }\end{array}$ \\
\hline IIIB & $\begin{array}{l}\text { Extension to pelvic sidewall and/or hydronephrosis or } \\
\text { non-functioning kidney }\end{array}$ & $\begin{array}{l}\text { Presence of tumour within } 3 \mathrm{~mm} \text { of internal obturator, levator ani } \\
\text { and pyriformis muscles or the iliac vessels. Additional signs are } \\
\text { increased SI and/or retraction of pelvic muscles, presence of } \\
\text { hydronephrosis due to ureteral obstruction at the level of the } \\
\text { primary tumour }\end{array}$ \\
\hline IV & $\begin{array}{l}\text { Tumour extends outside true pelvis or invades } \\
\text { bladder or rectal mucosa }\end{array}$ & \\
\hline IVA & Invasion of bladder or rectal mucosa & Tumour nodules protruding into the bladder/rectal lumen. \\
\hline IVB & Distant metastasis & $\begin{array}{l}\text { Tumour involving organs outside the true pelvis, includes the } \\
\text { para-aortic and inguinal nodes }\end{array}$ \\
\hline
\end{tabular}

SI signal intensity

centres offer chemoradiation for bulky tumours in place of surgery, despite an absence of parametrial spread.

Clinical examination is poor at estimating tumour size, especially when the tumour primarily occurs in the endocervix. MRI has been shown to be highly accurate in the assessement of tumour size, within $5 \mathrm{~mm}$ of the surgical size in $70-90 \%$ of cases [59], with an overall accuracy of $93 \%$ [60]. In a recent retrospective study of 150 surgically

Fig. 11a, b Endophytic cervical cancer Stage IB1. a Sagittal T2weighted image demonstrates an intermediate signal intensity mass within the endocervical canal (arrow). b Oblique axial T2-weighted image perpendicular to endocervical canal demonstrates tumour surrounded by an intact ring of cervical stroma (arrow)
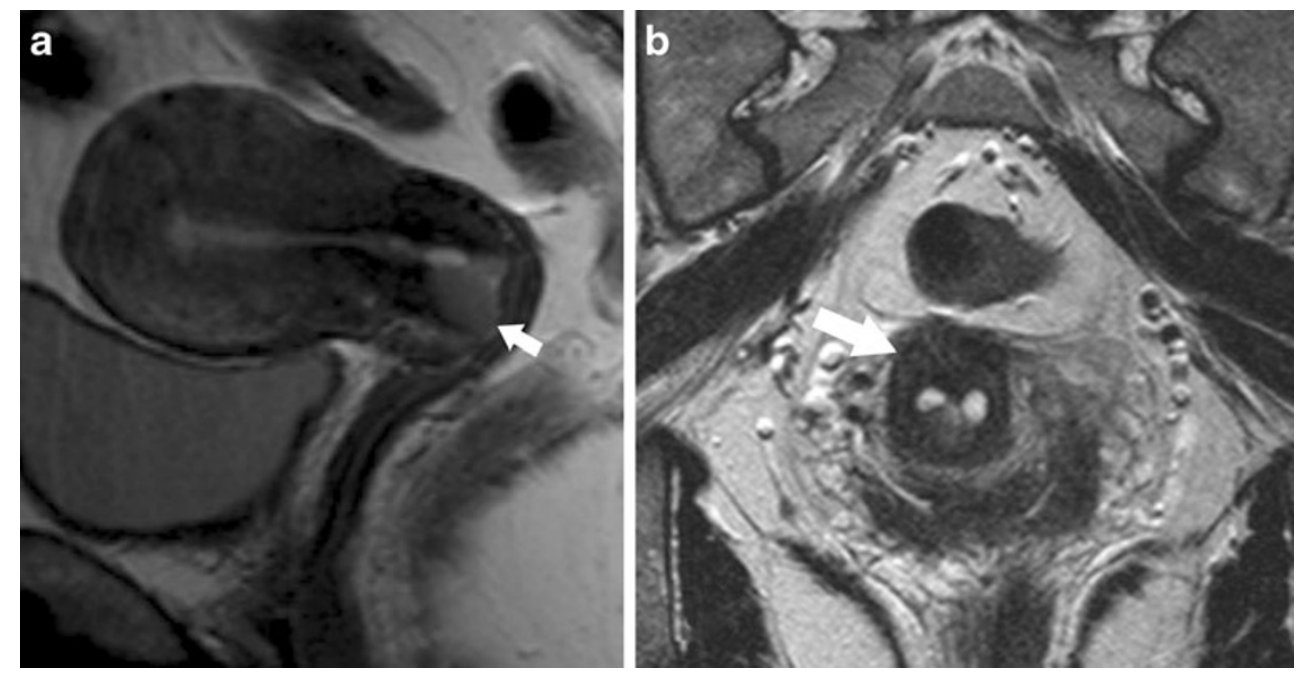
Fig. 12a, b Exophytic cervical cancer Stage IB2. a Sagittal T2weighted image showing a exophytic tumour $(T)$ greater than $4 \mathrm{~cm}$ arising from the posterior lip of the cervix. b Oblique axial $\mathrm{T} 2$-weighted image showing that although the tumour has breeched the cervical stromal ring (asterisk) it is still surrounded by the vaginal wall (arrows)
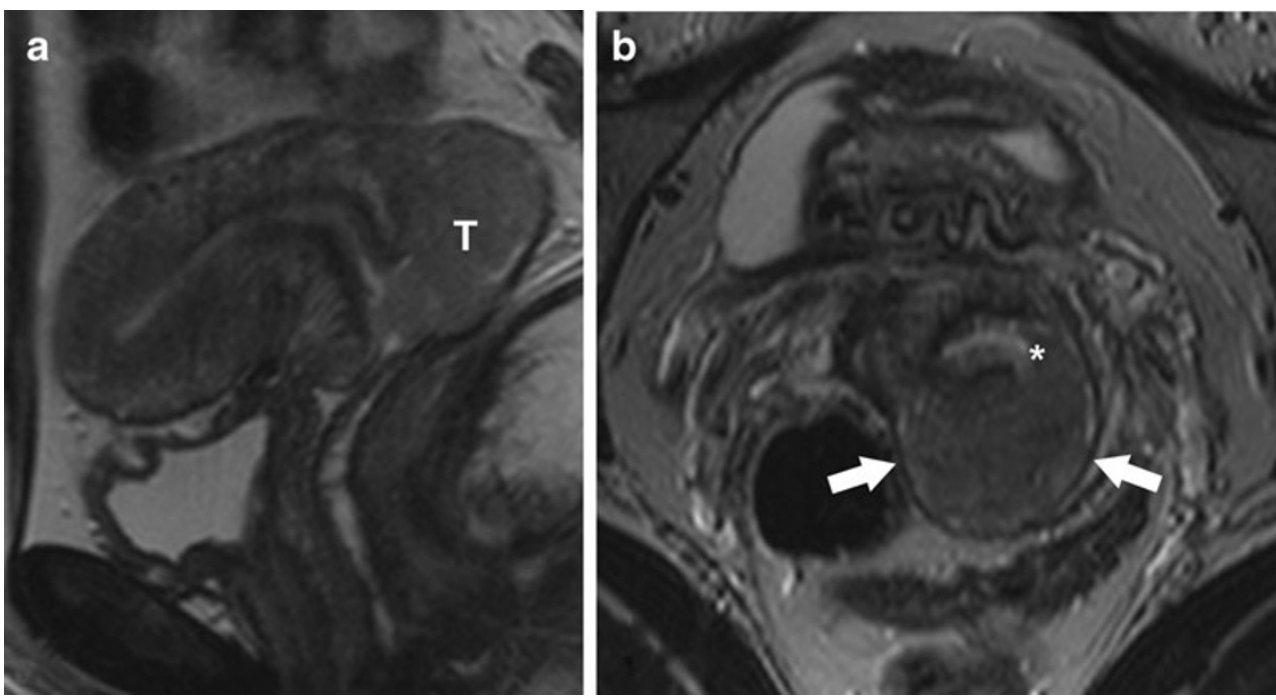

staged patients carried out in our own institution, the mean difference in tumour size between MRI and histology was $0.9 \mathrm{~mm}$, with $95 \%$ limits of agreement between -12.6 to $+13 \mathrm{~mm}$. In tumours greater than $10 \mathrm{~mm}$, mean difference was $0.3 \mathrm{~mm}$ and limits of agreement were -7.5 to $+7.9 \mathrm{~mm}$ [61]. This has important implications for delineation of the gross tumour volume for radiotherapy and for assessing the feasibility of uterus-preserving surgery.

\section{Stage II}

In Stage IIA, tumour infiltrates the upper two-thirds of the vagina without parametrial invasion. On MRI there is thickening and loss of the normal low signal intensity vaginal wall, in contiguity with the tumour mass (Fig. 13).

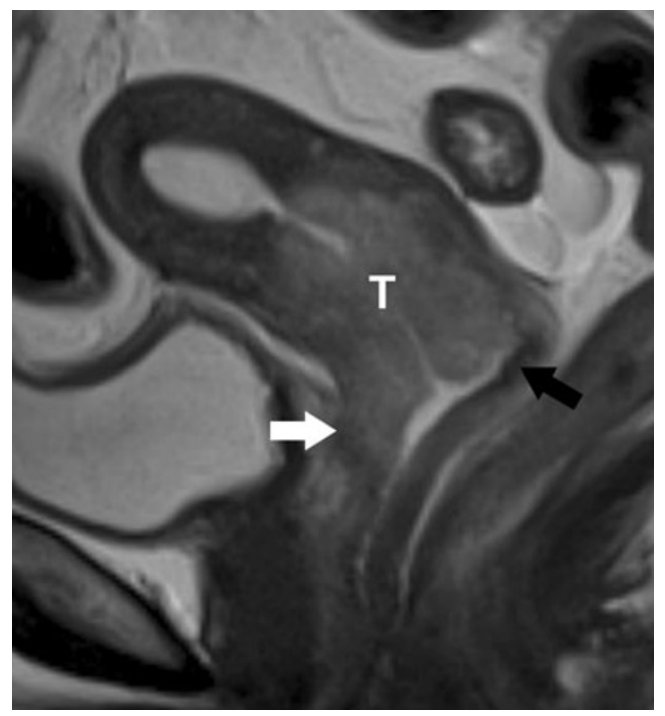

Fig. 13 Cervical cancer Stage IIA2. Sagittal T2-weighted image showing a 'barrel-shaped' cervical tumour $(T)$ that extends into the upper anterior vagina (white arrow). The normal posterior vagina has a low signal intensity (black arrow)
A common source of confusion are large exophytic tumours that distend the vagina and are misinterpreted to represent vaginal involvement. Compared with clinical examination, MRI is highly sensitive (86-93\%) in the depiction of vaginal infiltration [60]. FIGO now divides Stage II into IIA and IIB as the prognosis of large primary tumours $(>4 \mathrm{~cm})$ and vaginal infiltration has a worse prognosis than if the primary tumour is less than $4 \mathrm{~cm}$.

Parametrial invasion indicates Stage IIB disease. The radiological sign for parametrial invasion is breach of the low signal intensity ring of cervical stroma, best demonstrated on oblique axial high resolution images (Fig. 14). Additional features include a spiculated tumour-parametrium interface, soft tissue extension into the parametria and along the cardinal or uterosacral ligaments, encasement of the periuterine vessels; and in some cases the cervix may be pulled over to the side with parametrial invasion [62].

A common pitfall is the presence of a bulky exophytic tumour arising from the vaginal portion of the cervix. In this situation, disruption of the cervical stromal ring does not necessarily indicate parametrial invasion because the tumour may still be separated from the parametrium by the vaginal fornix (Fig. 12).

The accuracy for detection of parametrial invasion on MRI ranges from 88 to $97 \%$, sensitivity ranges $44-100 \%$, and specificity $80-97 \%[59,61,63-66]$. Preservation of the low signal intensity ring virtually excludes parametrial invasion with a negative predictive value of $94-100 \%$ [61, $62,64]$. However, the positive predictive value of disruption of the stromal ring is lower $(82-86 \%)[67,68]$ as it can be difficult to differentiate peritumoural oedema from parametrial invasion, particularly in large tumours. It is the ability to rule out parametrial invasion on MRI with a high negative predictive value, which is of greatest value clinically as it confidently identifies patients suitable for radical surgery. 
Fig. 14a, b Barrel-shaped cervical cancer Stage IIB. a Sagittal T2-weighted image demonstrate a large tumour $(T)$ which diffusely infiltrates the whole cervix circumferentially. b Oblique axial $\mathrm{T} 2$-weighted image demonstrates disruption of the low signal cervical stroma ring (short arrow) and shows the tumour extending into the right parametrium (long arrow)
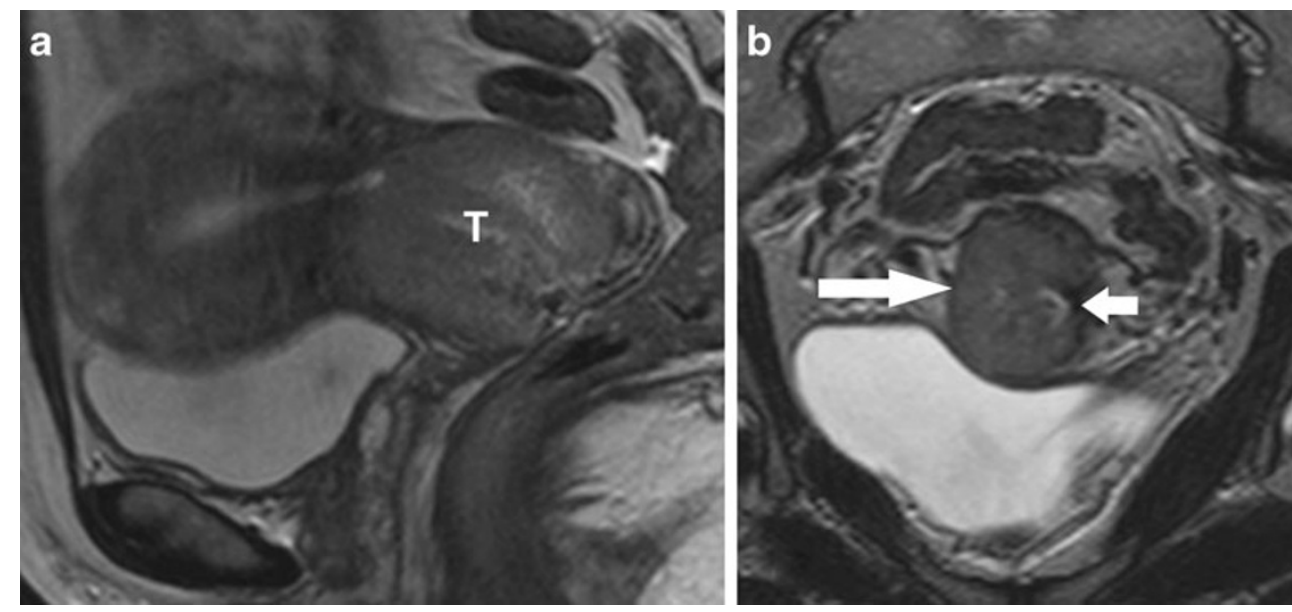

Stage III

In Stage IIIA, tumour extends down to the lower third of the vaginal wall (Fig. 15). When tumour extends to the pelvic sidewall or causes hydronephrosis, it is classified as Stage IIIB (Fig. 16). Pelvic sidewall involvement is defined as tumour within $3 \mathrm{~mm}$ of the obturator internus, levator ani, and pyriformis muscles or the iliac vessels [69].

\section{Stage IV}

In Stage IVA, the tumour invades the bladder (Fig. 17) or rectal mucosa (Fig. 18). Due to the relative 'bare area' of bladder posteriorly below the level of the peritoneal reflection, bladder invasion is more common than infiltration of the rectal wall as a deep peritoneal reflection and

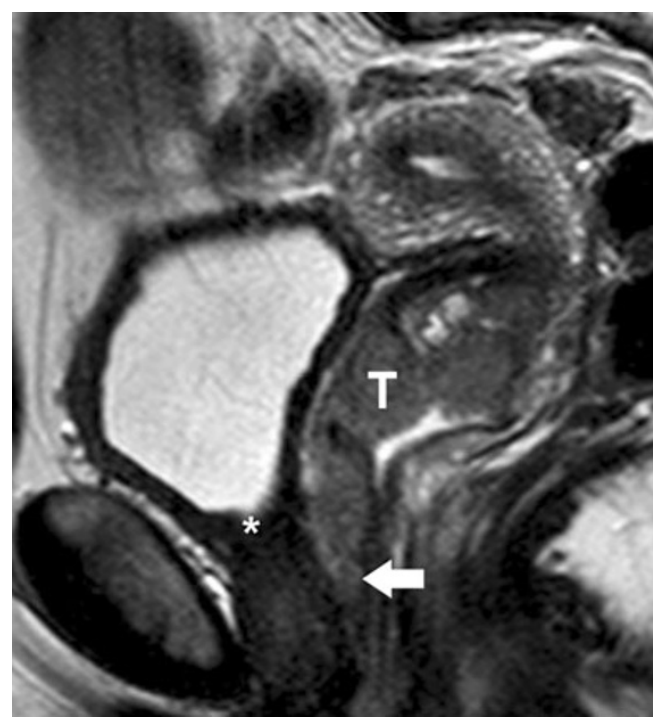

Fig. 15 Cervical cancer Stage IIIA. Sagittal T2-weighted image showing a cervical tumour $(T)$ that extends into the lower third of the vagina (arrow). The division between the upper and lower two-thirds of the vagina is approximately at the level of insertion of the urethra into the bladder base (asterisk) rectovaginal septum are interposed. Rectal invasion usually occurs via the uterosacral ligaments [70]. Contiguous extension of tumour from the cervix to the wall of the bladder or rectum, with loss of the intervening fat plane, may indicate serosal involvement. Focal or diffuse disruption of the normal low signal intensity muscle wall, resulting in a nodular or irregular appearance, suggests muscle invasion of the bladder or rectum. Mucosal invasion is seen as overt masses protruding into the lumen. Bullous oedema of the bladder is indicative of a nonspecific mucosal reaction to impaired perfusion, and raises the suspicion of bladder wall invasion but is not diagnostic of mucosal invasion.

The reported sensitivity of MRI in the evaluation of bladder or rectal invasion is $71-100 \%$, and the specificity is $88-91 \%$ [58, 60, 71]. If a low threshold for reporting bladder and rectal invasion is adopted, MRI has been shown to have a very high negative predictive value of $100 \%$ [58], thereby negating the need for invasive cystoscopic or endoscopic staging.

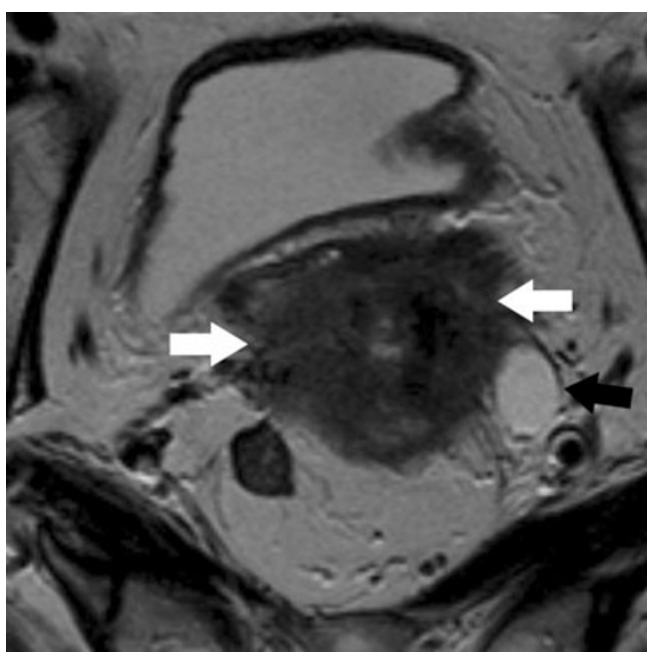

Fig. 16 Cervical cancer Stage IIIB. Oblique axial T2-weighted image demonstrates tumour invading the parametrium bilaterally (white arrows) and the left ureter (black arrow) causing ureteral obstruction 


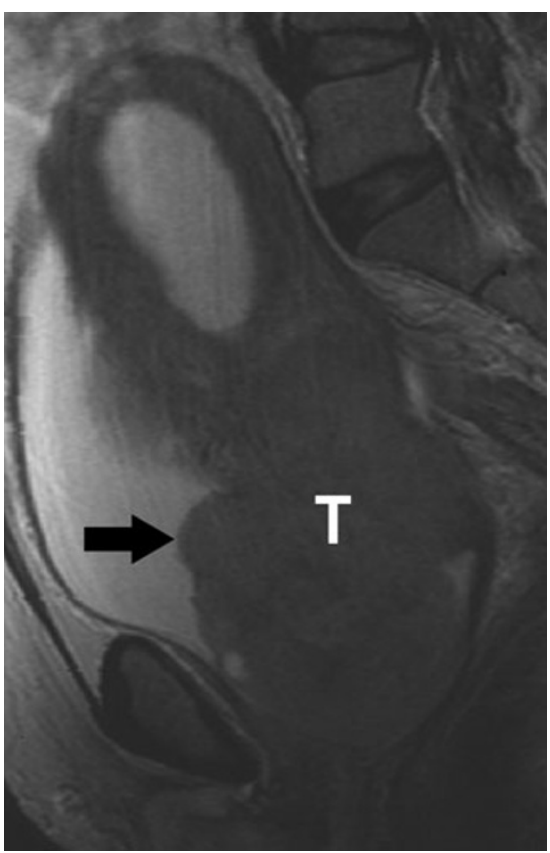

Fig. 17 Cervical cancer Stage IVA with bladder invasion. Sagittal T2weighted image demonstrates a large tumour $(T)$ in the cervix which invades the full width of the posterior bladder wall

Stage IVB indicates distant metastatic disease outside the true pelvis. Although pelvic node metastases do not change the FIGO Stage, para-aortic or inguinal metastases are classified as Stage IVB (Fig. 19) and indicate a poorer prognosis.

\section{Performance of MRI and CT}

The overall staging accuracy of MRI ranges from 77 to $90 \%[59,60,63,71-73]$. In single institution studies, MRI performs better than $\mathrm{CT}$ in the depiction of parametrial invasion and overall staging accuracy $[57,71,72,74]$. A systematic review of 57 single institution studies also showed that MRI was more accurate than CT for overall staging of cervical cancer [71]. The sensitivity of MRI in detecting parametrial invasion was $74 \%$ compared with $55 \%$ for $\mathrm{CT}$, and for bladder and rectal invasion the sensitivities were $75 \%$ and $71 \%$ respectively, higher compared with CT [71]. The prospective multi-centre study undertaken by the American College of Radiology Imaging Network (ACRIN) and the Gynecologic Oncology Group (GOG) compared MRI and CT in the patients with early invasive cervical cancer. As the probability of extra-cervical disease was low, the study showed that contrast enhanced multi-detector CT was equivalent to MRI for overall preoperative staging. However, MRI performed significantly better for visualisation of the primary tumour and detection of parametrial invasion. In addition, CT has much greater inter-observer variability when compared with MRI [75]. MRI, therefore, has great advantages in assessing the feasibility for trachelectomy or for planning modern conformal radiotherapy.

Importance of proximal extension

Young women with early Stage I disease who wish to preserve fertility can be offered fertility preserving surgery or trachelectomy. In this procedure, the tumour-bearing cervix is removed and the uterine body is re-anastomsed to the vagina with insertion of a cerclage suture to maintain isthmic competency during pregnancy [76]. An important criterion for surgery is that the proximal end of the tumour should be $1 \mathrm{~cm}$ or more distal to the internal os to permit tumour-free re-anastomosis. This cannot be reliably determined clinically by the examining gynaecologist, and MRI has been shown to be a reliable method of predicting involvement of the internal os by tumour, with a sensitivity

Fig. 18a, b Cervical cancer Stage IVA with rectal invasion. a Sagittal and $\mathbf{b}$ oblique axial T2-weighted images demonstrate a large tumour (white arrow) which extends through the fat plane between the cervix and rectum. The rectum and mesorectum are extensively involved (black arrows)
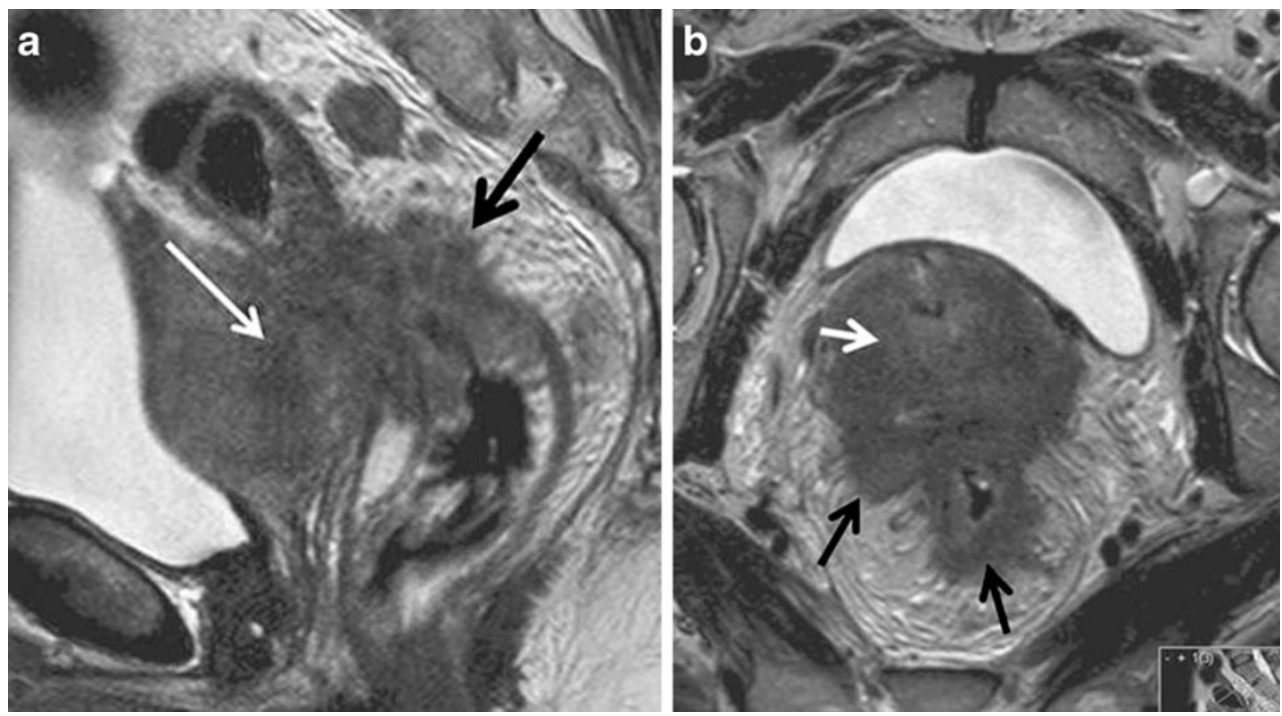
Fig. 19a, b Cervical cancer Stage IVB. a Axial oblique T2-weighted image showing a cervical tumour $(T)$ extending into the parametrium (white arrows), uterosacral ligament (asterisk) and posterior bladder wall (black arrow). b Axial contrast-enhanced $\mathrm{CT}$ in the same patient, showing an enlarged left para-aortic lymph node (arrow)
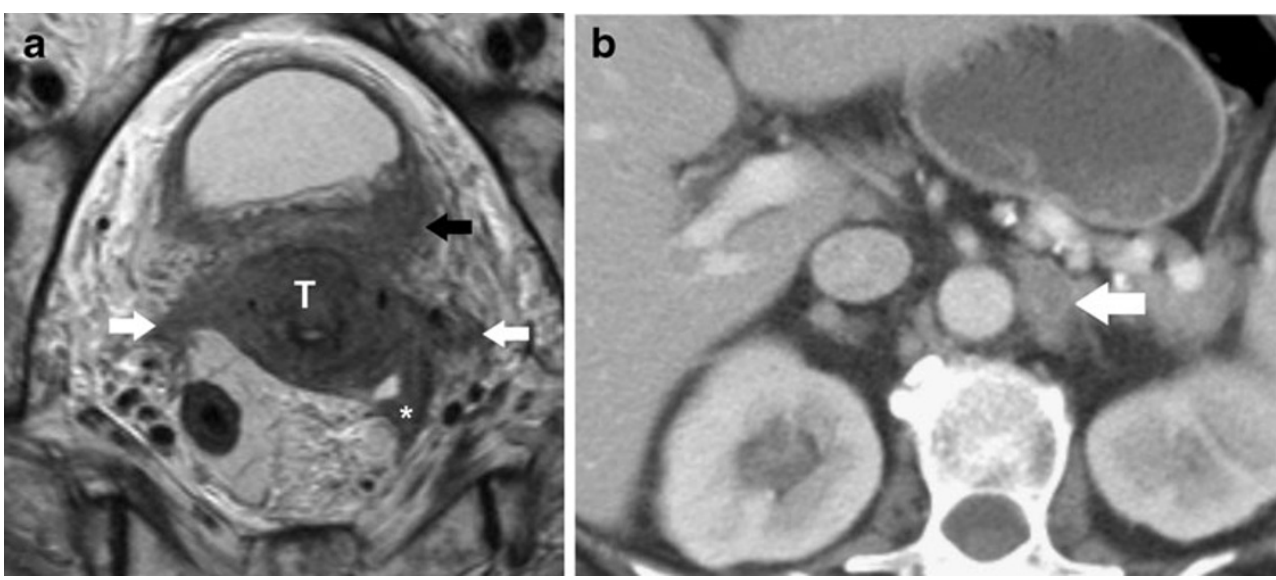

of $100 \%$ and specificity of $96 \%$ [77], making MRI essential when considering trachelectomy.

Proximal extension of tumour is also an important feature in predicting prognosis in patients with higher stage disease. In a study of 70 patients by Narayan et al. [78], the presence of proximal extension beyond the internal os and myometrial invasion as seen on MRI increased the probability of nodal metastases to $75 \%$ versus $11 \%$ in patients without proximal extension. Nodal metastases were considered to be involved with tumour if they demonstrated positive tracer uptake on FDG-PET scans. The presence of nodal metastases had a significant negative association with disease-specific and disease-free survival [78].

\section{Nodal metastases}

Within the pelvis, cervical cancer spreads first to parametrial nodes, then to obturator, internal and external iliac nodes. In more advanced disease, common iliac and paraaortic nodes may be involved. In a recent 25 -centre ACRIN/GOG study, lymphatic metastases were found in 55 of 161 women (34\%) with early invasive cervical cancer, verified by lymphadenectomy. Of these 55 women, $62 \%$ had metastases restricted to the low pelvis (defined as not involving the common iliac or above); $13 \%$ had common iliac metastases; and 9\% had para-aortic metastases [79]. Although not incorporated in the FIGO staging system, presence of lymph node metastases has significant prognostic and treatment consequences. The 5-year survival for node positive patients is $39-54 \%$ compared with 67 $92 \%$ in patients without nodal involvement $[80,81]$. In early stage tumour, involvement of any node is important as it excludes curative surgery changing the treatment to either chemoradiotherapy alone, or debulking surgery and neoadjuvant chemoradiotherapy. In higher stage tumours, detection of para-aortic nodes is important for planning the extent of the radiation field.

On cross-sectional imaging, size is the main criterion used to diagnose nodal metastasis and the most widely quoted threshold above which a node is considered malignant is $10 \mathrm{~mm}$ in short-axis diameter. Other features of malignancy include a round shape (for nodes with a short axis diameter of between 8 and $10 \mathrm{~mm}$ ) [82], central necrosis, soft tissue of the same signal intensity of the tumour within the node and extracapsular extension of tumour beyond the nodal capsule [83]. The presence of visible necrosis within the node, seen as pockets of high $\mathrm{T} 2$ signal intensity, has a positive predictive value of $100 \%$ for nodal involvement [84]. Conversely, a long thin shape and a fatty hilum are in favour of a benign node, even though enlarged.

MRI and CT have comparable overall accuracies in detecting nodal metastases [84]. Using standard size criteria, sensitivities on MRI are low, ranging from 29 to $86 \%[46,59,66,85]$. CT and MRI are unable to detect micrometastases in normal-sized nodes, and to differentiate reactive enlargement from malignant infiltration. The performance of MRI is greatly improved by use of lymph-node-specific MRI contrast agents, such as ultrasmall superparamagnetic iron oxide particles (USPIOs). These are intravenously administered to the patient at the time of the staging MRI. The contrast agent is transported via the interstitial space to lymph nodes, where they are taken up by normal macrophages. The presence of USPIOs within normal, macrophage-laden nodes results in loss of signal on T2-weighted sequences. In lymph nodes replaced by tumour deposits there is no loss of signal. The use of USPIOs improves the sensitivity of MRI (using standard size criteria of nodes) from $29 \%$ to $82-93 \%$, whilst maintaining a high specificity at $97 \%$ [46].

Studies into the diagnostic performance of FDG-PET/CT show varying results depending on the stage of the primary tumour. FDG-PET/CT has a sensitivity of $75-100 \%$ and specificity of $87-100 \%$ in advanced disease (FIGO IIB to IVB) $[67,86-88]$. In these patients FDG-PET also improves initial staging by demonstrating unexpected disease beyond the pelvis or retroperitoneum, such as supraclavicular nodal metastases [89], altering management 
in a significant number of patients [90]. In contrast, the value of FDG-PET in early-stage disease (FIGO I to IIA) is questionable. Many studies have reported low sensitivities for the detection of nodal metastases, ranging from $25-73 \%$ [91-94]. Chao et al. [90] concluded that PET/CT has a limited role in staging for patients with early-stage disease and should not replace lymphadenectomy for the detection of lymph node metastases. Overall, FDG-PET/CT is increasingly incorporated into cervical cancer management and a strong correlation has been found between pretreatment FDG-PET/CT lymph node status and patient diseasefree survival [95].

\section{Recurrent disease}

Cervical cancer recurrence is defined as local tumour regrowth or development of distant metastases at least 6 months after the primary lesion has regressed. Residual disease is that which is evident within 6 months of primary treatment. Approximately $30 \%$ of women with cervical cancer die of residual or recurrent disease after primary treatment [96]. Sixty percent of recurrences occur within the first 2 years following initial treatment, and $90 \%$ by 5 years [97]. The identification of recurrent disease is important, as salvage treatment has a 5-year survival rate of $46-52 \%$ compared with $5 \%$ in untreated disease [98]. The majority of recurrences occur in the central pelvis. A retrospective study in our own centre, evaluated MRI appearances of recurrent cervical cancer in 49 patients, of whom $70.4 \%$ recurred within 1 year following treatment. In patients receiving radiotherapy, $67 \%$ of recurrences were in the cervix, whilst $87 \%$ of post-surgical recurrences were in the vaginal vault. Only $13 \%$ of patients had recurrent disease outside the pelvis without evidence of pelvic disease [99].

Just as primary staging dictates initial management, location of recurrent disease, initial therapy and clinical condition of the patient will determine subsequent treatment. Local recurrent disease in the vaginal cuff (Fig. 20) or pelvic side walls (Fig. 21) after surgery may be treated with chemoradiotherapy. In patients who have already received chemoradiotherapy, central recurrence limited to the cervix and/or vagina may be treated with exenteration. Pelvic exenteration is reserved for young women with low co-morbidity and a central pelvic recurrence without peritoneal disease, vessel encasement, involvement of the pelvic sidewall or nodal metastases [100]. In the past CT was invaluable in predicting the feasibility of exenteration, but this has now been superceded by PET/CT. Distant metastatic disease may be treated with chemotherapy.

Due to its inherent contrast resolution MRI is superior in distinguishing radiation fibrosis from active disease and is of greater value than $\mathrm{CT}$ in identifying recurrent disease.

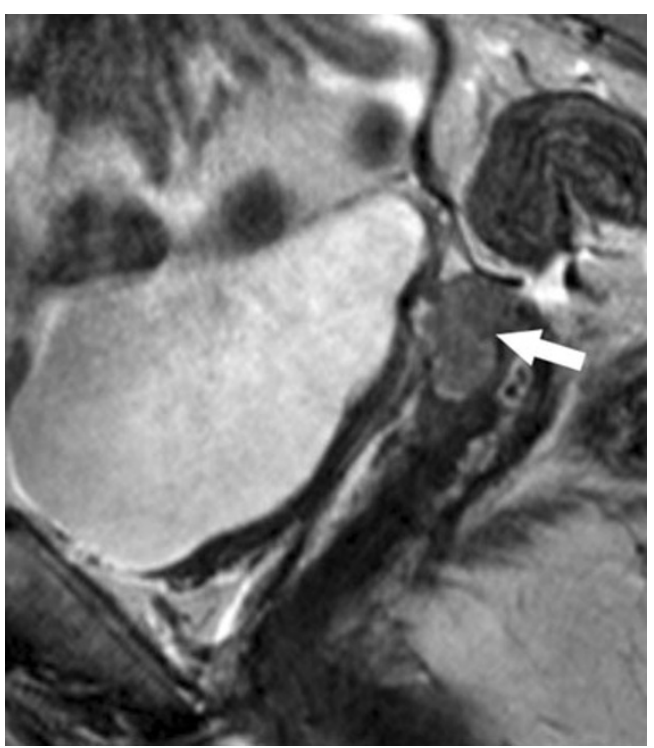

Fig. 20 Recurrent cervical cancer. Sagittal T2-weighted image showing a recurrent mass at the vaginal vault (arrow). This patient had localised central recurrence only and would therefore be suitable for pelvic exenteration

On MRI, recurrent disease appears as a mass of intermediate to high signal intensity on T2-weighted sequences; established radiotherapy fibrosis usually is of low signal intensity on $\mathrm{T} 2$-weighted sequences. However, differentiation can be difficult particularly in the first 6 months after radiotherapy when areas of high signal intensity may exist due to inflammation and oedema. Where morphological imaging is suboptimal in this differentiation, we have found that functional imaging aids diagnosis. These include dynamic contrast-enhanced MRI, diffusion weighted imaging and FDG-PET/CT.

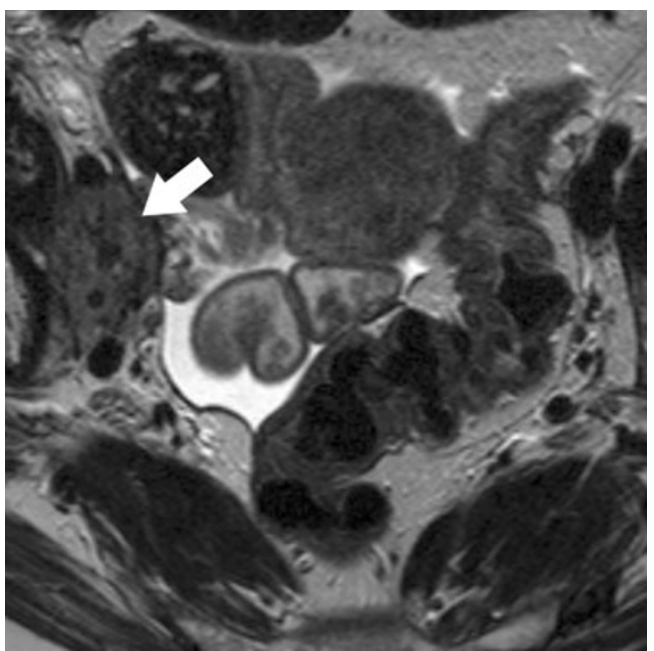

Fig. 21 Recurrent cervical cancer. Axial oblique T2-weighted image demonstrating a recurrent right pelvic side-wall mass (arrow). This encases the external iliac artery and vein and extends to the bony cortex. This would not be suitable for pelvic exenteration 
Dynamic contrast-enhanced MRI with analysis of signal intensity-time curves has been shown to improve the ability of MRI to detect tumour recurrence following radiotherapy. In a study by Kinkel et al. [101], comparing dynamic contrast-enhanced MRI with standard T2-weighted sequences, specificity and accuracy increased from $22 \%$ and $68 \%$ to $67 \%$ and $83 \%$ respectively. The optimal time to demonstrate tumour enhancement was between 45 and 90 s [101]. In patients with suspected recurrence clinically, FDG-PET/CT has been reported to be accurate in confirming the presence or absence of recurrent disease with sensitivities of $90.3-92.7 \%$ and specificities of $81-100 \%$ $[102,103]$. This is a higher sensitivity than CT and MRI alone for detecting recurrent disease.

The delineation of fistulae

MRI is preferable to $\mathrm{CT}$ in patients undergoing radiotherapy treatment to distinguish complications and effects of treatment from recurrent disease. Fistulae can occur as a result of primary or recurrent tumour or as consequence of surgery or radiotherapy and result in significant morbidity [104]. Vaginal fistulas are typically either vesicovaginal or enterovaginal, and are the most common type of fistula in patients with cervical cancer [105]. The appearance of a fistula on MRI depends on whether it is filled with fluid, air, or a combination of the two. On T2-weighted images, a fistula is typically seen as a high signal intensity fluid-filled communication (Fig. 22). An air-filled tract produces low signal intensity on MRI. The sagittal plane is preferred for the detection of vaginal fistulas as it allows optimal depiction of disruption of the posterior bladder wall in a vesicovaginal fistula and discontinuity of the posterior vaginal or anterior rectal wall in a rectovaginal fistula.

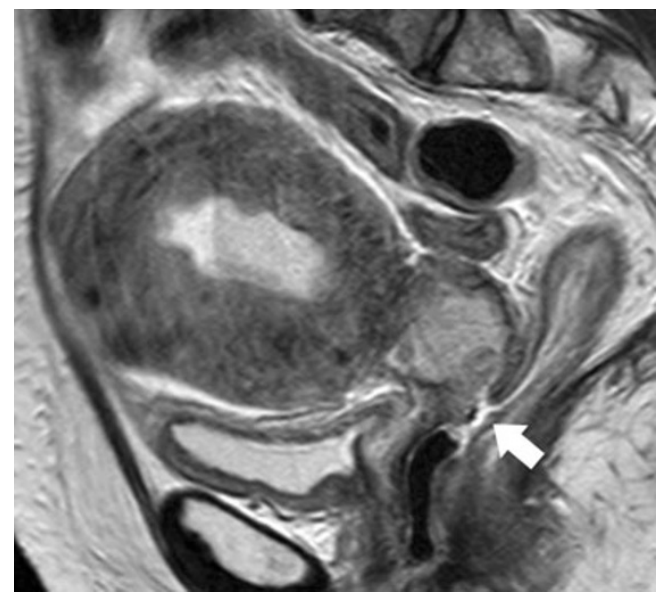

Fig. 22 Cervical cancer and rectovaginal fistulation. Sagittal T2weighted image demonstrates a large tumour which replaces the entire cervix and extends into the myometrium and upto the internal os. There is a fistula between the vagina and the anterior rectum containing fluid and air (arrow)

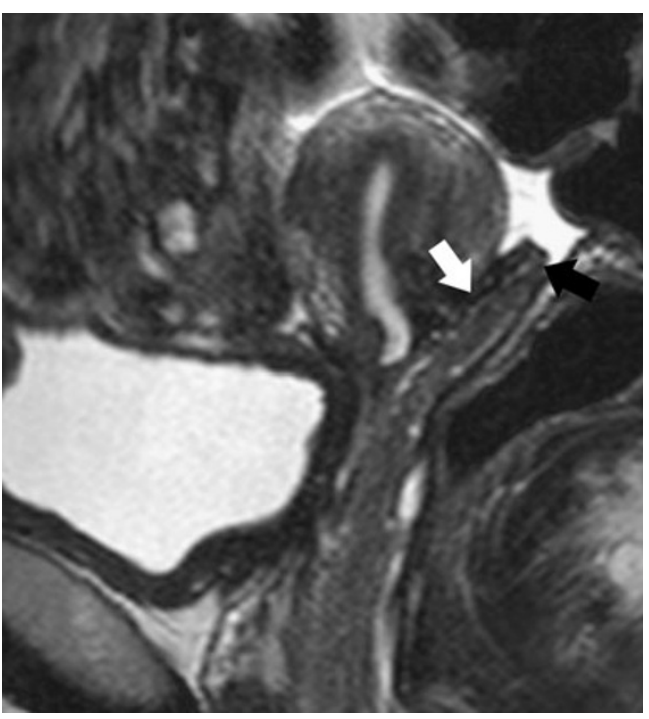

Fig. 23 Post-trachelectomy appearance. Sagittal T2-weighted image following fertility preserving surgery for early stage cervical cancer. The cervix has been removed with a cuff of vaginal fornix and parametrium. The lower uterine segment has been anastomsed onto the upper vagina (white arrow). Soft tissue posterior to the anastomosis is normal vaginal wall and represents a 'neo-fornix' (black arrow)

In a prospective study performed at our institution, 15 patients with clinical symptoms suggestive of a vaginal fistula were evaluated. MRI correctly indentified nine of the ten fistulae confirmed at surgery [106] and correctly differentiated between fistulae secondary to recurrence and those secondary to radiotherapy effects. Based on our results, we concluded that MRI is accurate in demonstrating the course, extent and complexity of vaginal fistulae, and in revealing associated active or recurrent disease.

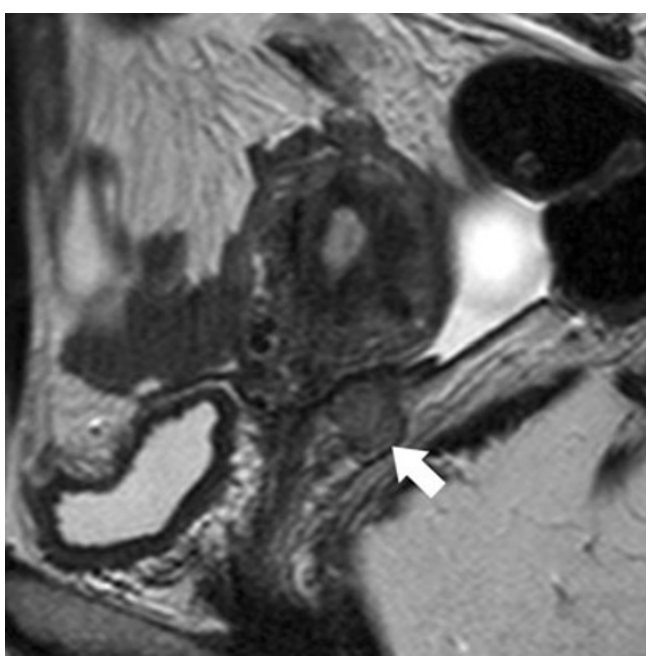

Fig. 24 Recurrent cervical cancer. Sagittal T2-weighted image showing a recurrent mass (arrow) at the utero-vaginal anastomosis in a patient who has had a previous trachelectomy 
Follow-up after trachelectomy

MRI is routinely used for surveillance to detect early recurrence in women who have undergone trachelectomy [107]. Recurrence rates following trachelectomy are low, with a figure of $4 \%$ quoted [108]. It is important to be aware of normal MRI postoperative appearances and to be able to discriminate between normal appearances (Fig. 23) and recurrent disease (Fig. 24) to avoid misinterpretation. In work carried out in our institution, three important appearances were observed after trachelectomy that should be recognised as normal and not recurrent disease [107]. In $56 \%$ of patients, there was a posterior 'puckering' of the vaginal wall, which the authors termed a 'neo-fornix' (Fig. 23). In 6\%, diffuse thickening of the vaginal wall was present up to 1 year after surgery and slowly resolved without treatment. Thirdly, 4\% of patients had slowly resolving haematomas in the vaginal wall. Suture artefacts also occur from uterovaginal anastomotic cerclage sutures used during the procedure. To date, these have not limited the diagnostic ability of MRI. Pelvic lymphocoeles and concurrent benign disease (endometriosis and adenomyosis) were also common findings.

\section{Planning radiotherapy}

Over the past few decades, advances in radiotherapy equipment have resulted in high-precision radiotherapy techniques, such as conformal and intensity-modulated radiotherapy (IMRT). The increased conformality of modern radiotherapy design necessitates improved means of delineating the tumour (gross tumour volume) for treatment. CT is the current standard imaging modality for radiotherapy planning but has inferior soft tissue contrast to MRI. The gross tumour volume on CT has been shown to be substantially larger than that measured on MRI [75]. It is crucial, therefore, that CT is correlated with MRI when defining the gross tumour volume. The co-registration of MRI and CT images with radiotherapy planning systems is the subject of ongoing research.

\section{Conclusion}

Imaging has assumed increasing importance in the management of patients with gynaecological cancer in recent years. This trend reflects a desire to obtain accurate staging and early disease detection to provide optimal treatment and minimise morbidity and mortality. MRI, although not officially incorporated in the FIGO staging system, is widely accepted as the most reliable imaging modality for staging and follow-up. In endometrial cancer, MRI is accurate in assessing the depth of myometrial extension and cervical extension, allowing for selective lymph node sampling or lymphadenectomy. In cervical cancer, MRI is important in local staging and in assessing proximal extension of tumours in young women for feasibility of fertility preserving surgery. In summary, the role of MRI is now well established, and future protocols may also incorporate functional imaging techniques that integrate both morphological and biological information which offer promise as early indicators of treatment response.

\section{References}

1. Amant F, Moerman P, Neven P, Timmerman D, Van Limbergen E, Vergote I (2005) Endometrial cancer. Lancet 366(9484):491-505

2. Kitchener HC, Trimble EL (2009) Endometrial cancer state of the science meeting. Int J Gynecol Cancer 19(1):134-140

3. Cancer Research UK. CancerStats. Available via http://info. cancerresearchuk.org/cancerstats/. Accessed 4 July 2010

4. Rose PG (1996) Endometrial carcinoma. N Engl J Med 335 (9):640-649

5. Polin SA, Ascher SM (2008) The effect of tamoxifen on the genital tract. Cancer Imaging 8:135-145

6. Epplein M, Reed SD, Voigt LF, Newton KM, Holt VL, Weiss NS (2008) Risk of complex and atypical endometrial hyperplasia in relation to anthropometric measures and reproductive history. Am J Epidemiol 168(6):563-570

7. Minagawa Y, Sato S, Ito M, Onohara Y, Nakamoto S, Kigawa J (2005) Transvaginal ultrasonography and endometrial cytology as a diagnostic schema for endometrial cancer. Gynecol Obstet Investig 59(3):149-154

8. Todo Y, Kato H, Kaneuchi M, Watari H, Takeda M, Sakuragi N (2010) Survival effect of para-aortic lymphadenectomy in endometrial cancer (SEPAL study): a retrospective cohort analysis. Lancet 375(9721):1165-1172

9. Kosary CL (1994) FIGO stage, histology, histologic grade, age and race as prognostic factors in determining survival for cancers of the female gynecological system: an analysis of 1973-87 SEER cases of cancers of the endometrium, cervix, ovary, vulva, and vagina. Semin Surg Oncol 10(1):31-46

10. Creasman WT, Morrow CP, Bundy BN, Homesley HD, Graham JE, Heller PB (1987) Surgical pathologic spread patterns of endometrial cancer. A Gynecologic Oncology Group Study. Cancer 60(8 Suppl):2035-2041

11. Sahdev A, Reznek RH (2008) Magnetic resonance imaging of endometrial and cervical cancer. Ann NY Acad Sci 1138:214-232

12. Creasman WT, DeGeest K, DiSaia PJ, Zaino RJ (1999) Significance of true surgical pathologic staging: a Gynecologic Oncology Group Study. Am J Obstet Gynecol 181(1):31-34

13. Shepherd JH (1989) Revised FIGO staging for gynaecological cancer. Br J Obstet Gynaecol 96(8):889-892

14. Pecorelli S (2009) Revised FIGO staging for carcinoma of the vulva, cervix, and endometrium. Int J Gynaecol Obstet 105(2):103-104

15. Creasman W (2009) Revised FIGO staging for carcinoma of the endometrium. Int J Gynaecol Obstet 105(2):109

16. Dowdy SC, Mariani A (2010) Lymphadenectomy in endometrial cancer: when, not if. Lancet 375(9721):1138-1140

17. McMeekin DS, Lashbrook D, Gold M, Scribner DR, Kamelle S, Tillmanns TD et al (2001) Nodal distribution and its significance in FIGO stage IIIc endometrial cancer. Gynecol Oncol 82(2):375-379

18. Tozzi R, Malur S, Koehler C, Schneider A (2005) Analysis of morbidity in patients with endometrial cancer: is there a commitment to offer laparoscopy? Gynecol Oncol 97(1):4-9 
19. Kitchener H, Swart AM, Qian Q, Amos C, Parmar MK (2009) Efficacy of systematic pelvic lymphadenectomy in endometrial cancer (MRC ASTEC trial): a randomised study. Lancet 373 (9658):125-136

20. Chan JK, Kapp DS (2007) Role of complete lymphadenectomy in endometrioid uterine cancer. Lancet Oncol 8(9):831-841

21. Roland PY, Kelly FJ, Kulwicki CY, Blitzer P, Curcio M, Orr JW $\mathrm{Jr}$ (2004) The benefits of a gynecologic oncologist: a pattern of care study for endometrial cancer treatment. Gynecol Oncol 93 (1):125-130

22. Benedetti PP, Basile S, Maneschi F, Alberto LA, Signorelli M, Scambia G et al (2008) Systematic pelvic lymphadenectomy vs. no lymphadenectomy in early-stage endometrial carcinoma: randomized clinical trial. J Natl Cancer Inst 100(23):1707-1716

23. Kong A, Powell M, Blake P (2008) The role of postoperative radiotherapy in carcinoma of the endometrium. Clin Oncol ( $R$ Coll Radiol) 20(6):457-462

24. Creutzberg CL, van Putten WL, Koper PC, Lybeert ML, Jobsen JJ, Warlam-Rodenhuis CC et al (2000) Surgery and postoperative radiotherapy versus surgery alone for patients with stage-1 endometrial carcinoma: multicentre randomised trial. PORTEC Study Group. Post Operative Radiation Therapy in Endometrial Carcinoma. Lancet 355(9213):1404-1411

25. Johnson N, Cornes P (2007) Survival and recurrent disease after postoperative radiotherapy for early endometrial cancer: systematic review and meta-analysis. BJOG 114(11):1313-1320

26. Nout RA, Smit VT, Putter H, Jurgenliemk-Schulz IM, Jobsen JJ, Lutgens LC et al (2010) Vaginal brachytherapy versus pelvic external beam radiotherapy for patients with endometrial cancer of high-intermediate risk (PORTEC-2): an open-label, noninferiority, randomised trial. Lancet 375(9717):816-823

27. Hardesty LA, Sumkin JH, Nath ME, Edwards RP, Price FV, Chang TS et al (2000) Use of preoperative MR imaging in the management of endometrial carcinoma: cost analysis. Radiology 215(1):45-49

28. Hricak H, Stern JL, Fisher MR, Shapeero LG, Winkler ML, Lacey CG (1987) Endometrial carcinoma staging by MR imaging. Radiology 162(2):297-305

29. Weber G, Merz E, Bahlmann F, Mitze M, Weikel W, Knapstein PG (1995) Assessment of myometrial infiltration and preoperative staging by transvaginal ultrasound in patients with endometrial carcinoma. Ultrasound Obstet Gynecol 6(5):362-367

30. Hardesty LA, Sumkin JH, Hakim C, Johns C, Nath M (2001) The ability of helical CT to preoperatively stage endometrial carcinoma. AJR Am J Roentgenol 176(3):603-606

31. Connor JP, Andrews JI, Anderson B, Buller RE (2000) Computed tomography in endometrial carcinoma. Obstet Gynecol 95(5):692-696

32. Kinkel K, Kaji Y, Yu KK, Segal MR, Lu Y, Powell CB et al (1999) Radiologic staging in patients with endometrial cancer: a meta-analysis. Radiology 212(3):711-718

33. Kim SH, Kim HD, Song YS, Kang SB, Lee HP (1995) Detection of deep myometrial invasion in endometrial carcinoma: comparison of transvaginal ultrasound, CT, and MRI. J Comput Assist Tomogr 19(5):766-772

34. Hricak H, Rubinstein LV, Gherman GM, Karstaedt N (1991) MR imaging evaluation of endometrial carcinoma: results of an NCI cooperative study. Radiology 179(3):829-832

35. Johnson W, Taylor MB, Carrington BM, Bonington SC, Swindell R (2007) The value of hyoscine butylbromide in pelvic MRI. Clin Radiol 62(11):1087-1093

36. Frei KA, Kinkel K, Bonel HM, Lu Y, Zaloudek C, Hricak H (2000) Prediction of deep myometrial invasion in patients with endometrial cancer: clinical utility of contrast-enhanced MR imaging - a meta-analysis and Bayesian analysis. Radiology 216 (2):444-449
37. Barwick TD, Rockall AG, Barton DP, Sohaib SA (2006) Imaging of endometrial adenocarcinoma. Clin Radiol 61 (7):545-555

38. Scoutt LM, McCarthy SM, Flynn SD, Lange RC, Long F, Smith $\mathrm{RC}$ et al (1995) Clinical stage I endometrial carcinoma: pitfalls in preoperative assessment with MR imaging. Work in progress. Radiology 194(2):567-572

39. Sironi S, Colombo E, Villa G, Taccagni G, Belloni C, Garancini $P$ et al (1992) Myometrial invasion by endometrial carcinoma: assessment with plain and gadolinium-enhanced MR imaging. Radiology 185(1):207-212

40. Rockall AG, Meroni R, Sohaib SA, Reynolds K, AlexanderSefre F, Shepherd JH et al (2007) Evaluation of endometrial carcinoma on magnetic resonance imaging. Int J Gynecol Cancer 17(1):188-196

41. Mariani A, Webb MJ, Keeney GL, Podratz KC (2001) Routes of lymphatic spread: a study of 112 consecutive patients with endometrial cancer. Gynecol Oncol 81(1):100-104

42. Ascher SM, Reinhold C (2002) Imaging of cancer of the endometrium. Radiol Clin North Am 40(3):563-576

43. Seki H, Azumi R, Kimura M, Sakai K (1997) Stromal invasion by carcinoma of the cervix: assessment with dynamic MR imaging. AJR Am J Roentgenol 168(6):1579-1585

44. Manfredi R, Mirk P, Maresca G, Margariti PA, Testa A, Zannoni GF et al (2004) Local-regional staging of endometrial carcinoma: role of MR imaging in surgical planning. Radiology 231(2):372378

45. Toki T, Oka K, Nakayama K, Oguchi O, Fujii S (1998) A comparative study of pre-operative procedures to assess cervical invasion by endometrial carcinoma. Br J Obstet Gynaecol 105 (5):512-516

46. Rockall AG, Sohaib SA, Harisinghani MG, Babar SA, Singh N, Jeyarajah AR et al (2005) Diagnostic performance of nanoparticleenhanced magnetic resonance imaging in the diagnosis of lymph node metastases in patients with endometrial and cervical cancer. J Clin Oncol 23(12):2813-2821

47. Park JY, Kim EN, Kim DY, Suh DS, Kim JH, Kim YM et al (2008) Comparison of the validity of magnetic resonance imaging and positron emission tomography/computed tomography in the preoperative evaluation of patients with uterine corpus cancer. Gynecol Oncol 108(3):486-492

48. Sohaib SA, Houghton SL, Meroni R, Rockall AG, Blake P, Reznek RH (2007) Recurrent endometrial cancer: patterns of recurrent disease and assessment of prognosis. Clin Radiol 62 (1):28-34

49. Franchi M, La Fianza A, Babilonti L, Bolis PF, Alerci M, Di Giulio G et al (1989) Clinical value of computerized tomography (CT) in assessment of recurrent uterine cancers. Gynecol Oncol 35(1):31-37

50. Belhocine T, De Barsy C, Hustinx R, Willems-Foidart J (2002) Usefulness of (18)F-FDG PET in the post-therapy surveillance of endometrial carcinoma. Eur J Nucl Med Mol Imaging 29 (9):1132-1139

51. Kitajima K, Suzuki K, Nakamoto Y, Onishi Y, Sakamoto S, Senda $M$ et al (2010) Low-dose non-enhanced CT versus fulldose contrast-enhanced CT in integrated PET/CT studies for the diagnosis of uterine cancer recurrence. Eur J Nucl Med Mol Imaging 37(8):1490-1498

52. Sigurdsson K (1993) Effect of organized screening on the risk of cervical cancer. Evaluation of screening activity in Iceland, 1964-1991. Int J Cancer 54(4):563-570

53. Stanley M (2008) Human papillomavirus vaccines versus cervical cancer screening. Clin Oncol (R Coll Radiol) 20(6):388-394

54. Pecorelli S, Zigliani L, Odicino F (2009) Revised FIGO staging for carcinoma of the cervix. Int J Gynaecol Obstet 105(2):107108 
55. Lagasse LD, Creasman WT, Shingleton HM, Ford JH, Blessing JA (1980) Results and complications of operative staging in cervical cancer: experience of the Gynecologic Oncology Group. Gynecol Oncol 9(1):90-98

56. Van NJ Jr, Roddick JW Jr, Lowin DM (1971) The staging of cervical cancer: inevitable discrepancies between clinical staging and pathologic findinges. Am J Obstet Gynecol 110(7):973-978

57. Hricak H, Powell CB, Yu KK, Washington E, Subak LL, Stern JL et al (1996) Invasive cervical carcinoma: role of MR imaging in pretreatment work-up-cost minimization and diagnostic efficacy analysis. Radiology 198(2):403-409

58. Rockall AG, Ghosh S, Alexander-Sefre F, Babar S, Younis MT, $\mathrm{Naz} S$ et al (2006) Can MRI rule out bladder and rectal invasion in cervical cancer to help select patients for limited EUA? Gynecol Oncol 101(2):244-249

59. Subak LL, Hricak H, Powell CB, Azizi L, Stern JL (1995) Cervical carcinoma: computed tomography and magnetic resonance imaging for preoperative staging. Obstet Gynecol 86(1):43-50

60. Hricak H, Lacey CG, Sandles LG, Chang YC, Winkler ML, Stern JL (1988) Invasive cervical carcinoma: comparison of MR imaging and surgical findings. Radiology 166(3):623-631

61. Sahdev A, Sohaib SA, Wenaden AE, Shepherd JH, Reznek RH (2007) The performance of magnetic resonance imaging in early cervical carcinoma: a long-term experience. Int $\mathrm{J}$ Gynecol Cancer 17(3):629-636

62. Kaur H, Silverman PM, Iyer RB, Verschraegen CF, Eifel PJ, Charnsangavej C (2003) Diagnosis, staging, and surveillance of cervical carcinoma. AJR Am J Roentgenol 180(6):1621-1631

63. Sheu MH, Chang CY, Wang JH, Yen MS (2001) Preoperative staging of cervical carcinoma with MR imaging: a reappraisal of diagnostic accuracy and pitfalls. Eur Radiol 11(9):1828-1833

64. Lam WW, So NM, Yang WT, Metreweli C (2000) Detection of parametrial invasion in cervical carcinoma: role of short tau inversion recovery sequence. Clin Radiol 55(9):702-707

65. Sironi S, Belloni C, Taccagni GL, DelMaschio A (1991) Carcinoma of the cervix: value of MR imaging in detecting parametrial involvement. AJR Am J Roentgenol 156(4):753-756

66. Chung HH, Kang SB, Cho JY, Kim JW, Park NH, Song YS et al (2007) Can preoperative MRI accurately evaluate nodal and parametrial invasion in early stage cervical cancer? Jpn J Clin Oncol 37(5):370-375

67. Lin WC, Hung YC, Yeh LS, Kao CH, Yen RF, Shen YY (2003) Usefulness of (18)F-fluorodeoxyglucose positron emission tomography to detect para-aortic lymph nodal metastasis in advanced cervical cancer with negative computed tomography findings. Gynecol Oncol 89(1):73-76

68. Kaji Y, Sugimura K, Kitao M, Ishida T (1994) Histopathology of uterine cervical carcinoma: diagnostic comparison of endorectal surface coil and standard body coil MRI. J Comput Assist Tomogr 18(5):785-792

69. Hricak H, Yu KK (1996) Radiology in invasive cervical cancer. AJR Am J Roentgenol 167(5):1101-1108

70. Taylor MB, Carrington BM, Davidson SE, Swindell R, Lawrance JA (2003) Staging of advanced cervical carcinoma using MRI-predictors of outcome after radical radiotherapy. Clin Radiol 58(7):532-541

71. Bipat S, Glas AS, van der Velden J, Zwinderman AH, Bossuyt PM, Stoker J (2003) Computed tomography and magnetic resonance imaging in staging of uterine cervical carcinoma: a systematic review. Gynecol Oncol 91(1):59-66

72. Kim SH, Choi BI, Han JK, Kim HD, Lee HP, Kang SB et al (1993) Preoperative staging of uterine cervical carcinoma: comparison of CT and MRI in 99 patients. J Comput Assist Tomogr 17(4):633-640

73. Cobby M, Browning J, Jones A, Whipp E, Goddard P (1990) Magnetic resonance imaging, computed tomography and endo- sonography in the local staging of carcinoma of the cervix. Br J Radiol 63(753):673-679

74. Kim SH, Choi BI, Lee HP, Kang SB, Choi YM, Han MC et al (1990) Uterine cervical carcinoma: comparison of CT and MR findings. Radiology 175(1):45-51

75. Hricak H, Gatsonis C, Coakley FV, Snyder B, Reinhold C, Schwartz LH et al (2007) Early invasive cervical cancer: CT and MR imaging in preoperative evaluation-ACRIN/GOG comparative study of diagnostic performance and interobserver variability. Radiology 245(2):491-498

76. Shepherd JH, Crawford RA, Oram DH (1998) Radical trachelectomy: a way to preserve fertility in the treatment of early cervical cancer. Br J Obstet Gynaecol 105(8):912-916

77. Peppercorn PD, Jeyarajah AR, Woolas R, Shepherd JH, Oram DH, Jacobs IJ et al (1999) Role of MR imaging in the selection of patients with early cervical carcinoma for fertility-preserving surgery: initial experience. Radiology 212(2):395-399

78. Narayan K, McKenzie AF, Hicks RJ, Fisher R, Bernshaw D, Bau S (2003) Relation between FIGO stage, primary tumor volume, and presence of lymph node metastases in cervical cancer patients referred for radiotherapy. Int J Gynecol Cancer 13(5):657-663

79. Mitchell DG, Snyder B, Coakley F, Reinhold C, Thomas G, Amendola MA et al (2009) Early invasive cervical cancer: MRI and CT predictors of lymphatic metastases in the ACRIN 6651/ GOG 183 intergroup study. Gynecol Oncol 112(1):95-103

80. Aoki Y, Sasaki M, Watanabe M, Sato T, Tsuneki I, Aida $\mathrm{H}$ et al (2000) High-risk group in node-positive patients with stage IB, IIA, and IIB cervical carcinoma after radical hysterectomy and postoperative pelvic irradiation. Gynecol Oncol 77(2):305-309

81. Odunsi KO, Lele S, Ghamande S, Seago P, Driscoll DL (2001) The impact of pre-therapy extraperitoneal surgical staging on the evaluation and treatment of patients with locally advanced cervical cancer. Eur J Gynaecol Oncol 22(5):325-330

82. Jager GJ, Barentsz JO, Oosterhof GO, Witjes JA, Ruijs SJ (1996) Pelvic adenopathy in prostatic and urinary bladder carcinoma: MR imaging with a three-dimensional TI-weighted magnetization-prepared-rapid gradient-echo sequence. AJR Am J Roentgenol 167(6):1503-1507

83. Barentsz JO, Jager GJ, van Vierzen PB, Witjes JA, Strijk SP, Peters $H$ et al (1996) Staging urinary bladder cancer after transurethral biopsy: value of fast dynamic contrast-enhanced MR imaging. Radiology 201(1):185-193

84. Yang WT, Lam WW, Yu MY, Cheung TH, Metreweli C (2000) Comparison of dynamic helical CT and dynamic MR imaging in the evaluation of pelvic lymph nodes in cervical carcinoma. AJR Am J Roentgenol 175(3):759-766

85. Hancke K, Heilmann V, Straka P, Kreienberg R, Kurzeder C (2008) Pretreatment staging of cervical cancer: is imaging better than palpation?: Role of CT and MRI in preoperative staging of cervical cancer: single institution results for 255 patients. Ann Surg Oncol 15(10):2856-2861

86. Rose PG, Adler LP, Rodriguez M, Faulhaber PF, Abdul-Karim FW, Miraldi F (1999) Positron emission tomography for evaluating para-aortic nodal metastasis in locally advanced cervical cancer before surgical staging: a surgicopathologic study. J Clin Oncol 17(1):41-45

87. Sugawara Y, Eisbruch A, Kosuda S, Recker BE, Kison PV, Wahl RL (1999) Evaluation of FDG PET in patients with cervical cancer. J Nucl Med 40(7):1125-1131

88. Loft A, Berthelsen AK, Roed H, Ottosen C, Lundvall L, Knudsen J et al (2007) The diagnostic value of PET/CT scanning in patients with cervical cancer: a prospective study. Gynecol Oncol 106(1):29-34

89. Magne N, Chargari C, Vicenzi L, Gillion N, Messai T, Magne J et al (2008) New trends in the evaluation and treatment of cervix cancer: the role of FDG-PET. Cancer Treat Rev 34(8):671-681 
90. Chao A, Ho KC, Wang CC, Cheng HH, Lin G, Yen TC et al (2008) Positron emission tomography in evaluating the feasibility of curative intent in cervical cancer patients with limited distant lymph node metastases. Gynecol Oncol 110(2):172-178

91. Park W, Park YJ, Huh SJ, Kim BG, Bae DS, Lee J et al (2005) The usefulness of MRI and PET imaging for the detection of parametrial involvement and lymph node metastasis in patients with cervical cancer. Jpn J Clin Oncol 35 (5):260-264

92. Chou HH, Chang TC, Yen TC, Ng KK, Hsueh S, Ma SY et al (2006) Low value of [18F]-fluoro-2-deoxy-D-glucose positron emission tomography in primary staging of early-stage cervical cancer before radical hysterectomy. J Clin Oncol 24 (1):123-128

93. Sironi S, Buda A, Picchio M, Perego P, Moreni R, Pellegrino A et al (2006) Lymph node metastasis in patients with clinical early-stage cervical cancer: detection with integrated FDG PET/ CT. Radiology 238(1):272-279

94. Wright JD, Dehdashti F, Herzog TJ, Mutch DG, Huettner PC, Rader JS et al (2005) Preoperative lymph node staging of early-stage cervical carcinoma by [18F]-fluoro-2-deoxy-D-glucose-positron emission tomography. Cancer 104(11):2484-2491

95. Grigsby PW, Siegel BA, Dehdashti F (2001) Lymph node staging by positron emission tomography in patients with carcinoma of the cervix. J Clin Oncol 19(17):3745-3749

96. Cannistra SA, Niloff JM (1996) Cancer of the uterine cervix. N Engl J Med 334(16):1030-1038

97. Halpin TF, Frick HC, Munnell EW (1972) Critical points of failure in the therapy of cancer of the cervix: a reappraisal. Am J Obstet Gynecol 114(6):755-764

98. Shepherd JH, Ngan HY, Neven P, Fryatt I, Woodhouse CR, Hendry WF (1994) Multivariate analysis of factors affecting survival in pelvic exenteration. Int J Gynecol Cancer 4(6):361-370
99. Babar S, Rockall A, Goode A, Shepherd J, Reznek R (2007) Magnetic resonance imaging appearances of recurrent cervical carcinoma. Int J Gynecol Cancer 17(3):637-645

100. Popovich MJ, Hricak H, Sugimura K, Stern JL (1993) The role of MR imaging in determining surgical eligibility for pelvic exenteration. AJR Am J Roentgenol 160(3):525-531

101. Kinkel K, Ariche M, Tardivon AA, Spatz A, Castaigne D, Lhomme $C$ et al (1997) Differentiation between recurrent tumor and benign conditions after treatment of gynecologic pelvic carcinoma: value of dynamic contrast-enhanced subtraction MR imaging. Radiology 204(1):55-63

102. Chung HH, Jo H, Kang WJ, Kim JW, Park NH, Song YS et al (2007) Clinical impact of integrated PET/CT on the management of suspected cervical cancer recurrence. Gynecol Oncol 104(3):529-534

103. Sironi S, Picchio M, Landoni C, Galimberti S, Signorelli M, Bettinardi V et al (2007) Post-therapy surveillance of patients with uterine cancers: value of integrated FDG PET/CT in the detection of recurrence. Eur J Nucl Med Mol Imaging 34(4):472-479

104. Narayanan P, Nobbenhuis M, Reynolds KM, Sahdev A, Reznek RH, Rockall AG (2009) Fistulas in malignant gynecologic disease: etiology, imaging, and management. Radiographics 29 (4):1073-1083

105. Emmert C, Kohler U (1996) Management of genital fistulas in patients with cervical cancer. Arch Gynecol Obstet 259(1):19 24

106. Healy JC, Phillips RR, Reznek RH, Crawford RA, Armstrong P, Shepherd JH (1996) The MR appearance of vaginal fistulas. AJR Am J Roentgenol 167(6):1487-1489

107. Sahdev A, Jones J, Shepherd JH, Reznek RH (2005) MR imaging appearances of the female pelvis after trachelectomy. Radiographics 25(1):41-52

108. Shepherd JH, Milliken DA (2008) Conservative surgery for carcinoma of the cervix. Clin Oncol (R Coll Radiol) 20(6):395-400 